\title{
Investigating the Spatial Associations Between Amyloid- $\beta$ Deposition, Grey Matter Volume, and Neuroinflammation in Alzheimer's Disease
}

\author{
Lília Jorge ${ }^{\mathrm{a}, \mathrm{b}}$, Ricardo Martins ${ }^{\mathrm{a}, \mathrm{b}}$, Nádia Canário ${ }^{\mathrm{a}, \mathrm{b}, \mathrm{c}}$, Carolina Xavier $^{\mathrm{a}, \mathrm{b}}$, Antero Abrunhosa ${ }^{\mathrm{a}, \mathrm{b}}$, \\ Isabel Santana ${ }^{\mathrm{c}, \mathrm{d}}$ and Miguel Castelo-Branco ${ }^{\mathrm{a}, \mathrm{b}, \mathrm{c}, *}$ \\ ${ }^{\mathrm{a}}$ Coimbra Institute for Biomedical Imaging and Translational Research (CIBIT), University of Coimbra, \\ Coimbra, Portugal \\ ${ }^{\mathrm{b}}$ Institute for Nuclear Sciences Applied to Health (ICNAS), University of Coimbra, Coimbra, Portugal \\ ${ }^{\mathrm{c}}$ Faculty of Medicine, University of Coimbra, Coimbra, Portugal \\ ${ }^{\mathrm{d}}$ Department of Neurology, Coimbra University Hospital, Coimbra, Portugal
}

Accepted 11 December 2020

Pre-press 23 January 2021

Handling Associate Editor: Josephine Barnes

\begin{abstract}
.
Background: It has been proposed that amyloid- $\beta(\mathrm{A} \beta)$ plays a causal role in Alzheimer's disease (AD) by triggering a series of pathologic events_-possibly including neuroinflammation—which culminate in progressive brain atrophy. However, the interplay between the two pathological molecular events and how both are associated with neurodegeneration is still unclear. Objective: We aimed to estimate the spatial inter-relationship between neurodegeneration, neuroinflammation and $A \beta$ deposition in a cohort of 20 mild AD patients and 17 healthy controls (HC).

Methods: We resorted to magnetic resonance imaging to measure cortical atrophy, using the radiotracer ${ }^{11} \mathrm{C}-\mathrm{PK} 11195 \mathrm{PET}$ to measure neuroinflammation levels and ${ }^{11} \mathrm{C}-\mathrm{PiB}$ PET to assess $\mathrm{A} \beta$ levels. Between-group comparisons were computed to explore AD-related changes in the three types of markers. To examine the effects of each one of the molecular pathologic mechanisms on neurodegeneration we computed: 1) ANCOVAs with the anatomic data, controlling for radiotracer uptake differences between groups and 2) voxel-based multiple regression analysis between-modalities. In addition, associations in anatomically defined regions of interests were also investigated.

Results: We found significant differences between $\mathrm{AD}$ and controls in the levels of atrophy, neuroinflammation, and $\mathrm{A} \beta$ deposition. Associations between $\mathrm{A} \beta$ aggregation and brain atrophy were detected in AD in a widely distributed pattern, whereas associations between microglia activation and structural measures of neurodegeneration were restricted to few anatomically regions.

Conclusion: In summary, $A \beta$ deposition, as opposed to neuroinflammation, was more associated with cortical atrophy, suggesting a prominent role of $\mathrm{A} \beta$ in neurodegeneration at a mild stage of the AD.
\end{abstract}

Keywords: Alzheimer's disease, amyloid- $\beta$, magnetic resonance imaging, neuroinflammation, neurodegeneration, positron emission tomography

\footnotetext{
${ }^{*}$ Correspondence to: Miguel Castelo-Branco, Faculdade de Medicina, Polo Ciências da saúde da Universidade de Coimbra,
} 


\section{INTRODUCTION}

Alzheimer's disease (AD) is considered the most common form of dementia and the presence of amyloid- $\beta$ (A $\beta$ ) plaques and neurofibrillary tangles composed of hyperphosphorylated tau proteins are its key neuropathological hallmarks, leading to progressive brain atrophy [1, 2]. In addition, neuroinflammation, mediated by the activation of microglial cells, is also believed to be a pathological element of the disease [3, 4]. The activation of microglia cells is the intrinsic brain immune response to the pathological mechanisms occurring in the brain [5]. However, the exact role of microglia activation in the disease, as well as its time course and its interplay with $A \beta$ and cortical atrophy remains unclear. Nevertheless, in general it is suggested that microglial activation may play a protective role in the beginning of the disease by clearing $A \beta$, remodeling synapses and releasing growth factors [6-9]. But exceeding a certain level of activation it may became deleterious to the brain through cytokine release, which might promote tau hyperphosphorylation [10-12]. The comprehension of the role of neuroinflammation in $\mathrm{AD}$ is important as a biomarker for monitoring disease detection and progression, as well as for the development of therapeutic strategies.

A well-accepted theory proposes that abnormal $\mathrm{A} \beta$ accumulation causes synaptic dysfunction and neuronal loss, for which the exact mechanisms are still controversial [13], resulting in cognitive decline and dementia $[2,13]$. In turn, an alternative amyloid cascade/neuroinflammation theory postulates that the activation of microglia as response to $A \beta$ deposition leads to the release of neurotoxic substances, resulting in tau phosphorylation and neurodegenerative changes $[10,12]$. In fact, work on postmortem $\mathrm{AD}$ brains have found increased activated microglia near to amyloid plaques [14-18], as well as an association between these two processes [16], implying microglia in the pathogenesis and/or progression of the pathology.

Different radiotracers have been developed which are capable to measure $A \beta$ retention or activated microglia through positron emission tomography (PET), in vivo. The radiotracer ${ }^{11} \mathrm{C}-\mathrm{PK} 11195$ is a ligand to the Peripheral Benzodiazepine Receptor (PBR, also known as the ' $18 \mathrm{kDa}$ Translocator Protein' or 'TSPO'), a receptor abnormally expressed by the mitochondria of activated microglia [19]. ${ }^{11} \mathrm{C}$ Pittsburgh Compound-B (PiB) allows detection and quantification of $A \beta$ plaque aggregation, because it binds to fibrillar $\mathrm{A} \beta$ plaques found in the $\mathrm{AD}$ brain [20]. Whereas a widespread ${ }^{11} \mathrm{C}-\mathrm{PiB}$ cortical uptake has been consistently found in AD brains [20-23] results across studies on ${ }^{11} \mathrm{C}$-PK11195 PET tracer remain controversial $[24,25]$. Of those that found a significant presence of microglia activation, only a part has found it associated with $A \beta$ uptake [26-28].

Considering the current debate concerning the role of neuroinflammation in $\mathrm{AD}$, new studies are of utmost importance, namely in early AD stages, since the majority of the AD studies have focused on mildto-moderate $\mathrm{AD}$ patients. Although the literature suggests that both microglial activation and $A \beta$ deposition may lead to brain atrophy, it remains uncertain whether and how patterns of metabolic alterations correlate between them, i.e., how $A \beta$ relates with neuroinflammation and if they interact in promoting cortical neurodegeneration.

In the present study we aimed to address this issue by measuring grey matter (GM) volume to assess cortical atrophy using MRI, in conjunction with mapping $\mathrm{A} \beta$ deposition resorting to ${ }^{11} \mathrm{C}$-PiB PET imaging and microglia tracer ${ }^{11} \mathrm{C}-\mathrm{PK} 11195$ PET to evaluate brain neuroinflammation, in $\mathrm{AD}$ patients at a relatively early-stage and healthy matched subjects (gender, age, and education). To achieve this goal, we have first tested the between group differences in terms of GM volume, $A \beta$ load, and neuroinflammation, and thereafter we computed voxel-wise regression analysis and region of interest (ROI)-based correlation analysis to investigate the spatial relationships between the three modalities of brain imaging. Clarifying these relationships in AD could provide important insights into disease mechanisms and improve therapeutic approaches.

\section{METHODS}

\section{Participants}

For the present study, we recruited 41 individuals: 20 patients with early diagnosis (less than 2 years) of $\mathrm{AD}$, at the mild stage of dementia according to Clinical Dementia Rating $(\mathrm{CDR}=1)$, and 21 HC matched for age, sex, and education. We selected $\mathrm{AD}$ patients with a probable diagnosis supported by biological biomarkers (CSF and PiB-PET) from the Memory Clinic of the Centro Hospitalar e Universitário de Coimbra (CHUC), who were submitted to a comprehensive neuropsychological assessment, including: Cognitive instruments as the Mini-Mental 
State Examination (MMSE) with Portuguese normative data, the Montreal Cognitive Assessment (MoCA) and a comprehensive neuropsychological battery with normative data for the Portuguese population (BLAD) exploring memory and other cognitive domains.

The AD diagnosis was made according to the Diagnostic and Statistical Manual of Mental Disorders fourth edition (DSM-IV-TR) [29] and the National Institute of Neurological and Communicative Disorders and Stroke- Alzheimer's Disease and Related Disorders (NINCDS-ADRDA) [30]. Detailed clinical information about the AD group can be found in a previous work [31].

To the control group we recruited 21 healthy volunteers from the community without neurologic or psychiatric disorders, no severe visual or auditory impairment, and eligible to an MRI exam. In order to guarantee a normal cognitive status, this group was also submitted to a brief cognitive assessment. Thus, all HC had no significant memory complaints (Subjective Memory Complaints Questionnaire - SMC $\leq 3)[32,33]$, had a normal general cognitive function as tested by the MoCA (mean $\pm \mathrm{sd}, 24.88 \pm 4.24$ ) [34] preserved daily living activities (Lawton \& Brody scale $-\mathrm{L} \& B$ for Female $=8$; for Male $=5$ ) $[35$, $36]$, and no evidence of $[37,38]$ moderate or severe depressive symptoms (30-item Geriatric Depressive Scale - GDS-30, mean \pm SD $6.41 \pm 6.20$ ). All participants underwent ${ }^{11} \mathrm{C}-\mathrm{PK} 11195 \mathrm{PET}$ and ${ }^{11} \mathrm{C}-\mathrm{PiB}$ PET imaging. Four participants from the control group were found positive for the ${ }^{11} \mathrm{C}-\mathrm{PiB}$ PET exam, being excluded from the subsequent analysis. In fact, about $30 \%$ of the normal elderly individuals' evidence significant levels of $\mathrm{A} \beta$ deposition short of clinically cognitive decline [39]. Thus, all $\mathrm{AD}$ patients were ${ }^{11} \mathrm{C}-\mathrm{PiB}$ PET positive while all the controls which were considered in this study were ${ }^{11} \mathrm{C}$-PiB PET negative. All subjects included in the study performed 3 visits to ICNAS-UC (Institute of Nuclear Sciences Applied to Health, University of Coimbra), where all imaging procedures were performed, in the first visit patients underwent MRI acquisition, while in the second and third visits, participants underwent ${ }^{11} \mathrm{C}-\mathrm{PiB}$ PET and ${ }^{11} \mathrm{C}-\mathrm{PK} 11195$ PET scans, respectively, with a maximum interval of 5 weeks between examinations.

The study was approved by the Ethics Committee of the Faculty of Medicine, University of Coimbra. All subjects participated voluntarily and gave their informed written consent for the study, following the tenets of the Declaration of Helsinki, after clarification of the nature and possible implications of the study.

\section{MRI imaging}

In the first visit, MRI data were collected using a Siemens Magnetom TIM Trio 3 Tesla scanner (Siemens, Munich, Germany) with a phased array 12-channel birdcage head coil. For all the participants, the MRI data acquisition protocol consisted of 3D structural MR imaging scans using a T1weighted MPRAGE (magnetization-prepared rapid gradient echo) magnetic resonance imaging pulse sequence (TR $2530 \mathrm{~ms}$; TE $3.42 \mathrm{~ms}$; TI $1100 \mathrm{~ms}$; flip angle $7^{\circ} ; 176$ single-shot interleaved slices with no gap with isotropic voxel size $1 \times 1 \times 1 \mathrm{~mm}$; FOV $256 \mathrm{~mm})$.

MRI data were pre-processed in SPM12 (Version 12, Wellcome Trust Centre for Neuroimaging, London, UK), and executed in MATLAB software (version 8.1.0 R2013a, The Mathworks, MA) through its computational anatomy toolbox (CAT12) (http://dbm.neuro.uni-jena.de/cat/), which allows fully automatic cortex segmentation for the posterior voxel-based morphometry (VBM) analysis.

In a first step, T1-weighted images were normalized to a template space and automatically segmented into GM, white matter (WM), and cerebrospinal fluid (CSF), relying on prior probability tissue maps, assigning to each voxel a value representing the proportion of the corresponding tissue type [40]. To the spatial normalization, the subject's brain was aligned to a standard MNI template, resorting to the highdimensional registration DARTEL algorithm [41], using linear affine transformation and further nonlinear warping. Thereon, in order to restore tissue volumes modified during normalization processing, Jacobian modulation was applied [42]. At the end of the automatic segmentation procedure, normalized GM maps were smoothed by an $8 \mathrm{~mm}$ FWHM kernel, helping to improve the inaccurate nature of the anatomical standardization.

\section{PET acquisition}

The ${ }^{11} \mathrm{C}$-PiB PET and ${ }^{11} \mathrm{C}$-PK11195 PET were acquired using a Philips Gemini GXL PET/CT scanner (Philips Medical Systems, Best, the Netherlands), during the second and third visits, respectively. In each visit, the participants performed the respective dynamic 3-dimensional PET scan of the entire brain ( 90 slices, $2 \mathrm{~mm}$ slice sampling) and 
a low-dose brain CT scan, for attenuation correction. The dynamic ${ }^{11} \mathrm{C}-\mathrm{PiB}$ PET image consists of 24 frames (total duration of $90 \mathrm{~min}$ : 37 frames: $4 \times 15 \mathrm{~s}$ $+8 \times 30 s+9 \times 60 s+2 \times 180 s+14 \times 300 s)$ and the dynamic ${ }^{11} \mathrm{C}-\mathrm{PK} 11195$ image of 22 frames (total duration of $60 \mathrm{~min}: 4 \times 30 \mathrm{~s}+4 \times 60 \mathrm{~s}+4 \times 120 \mathrm{~s}+$ $4 \times 240 \mathrm{~s}+6 \times 300 \mathrm{~s})$. The ${ }^{11} \mathrm{C}-\mathrm{PiB}$ PET or ${ }^{11} \mathrm{C}$ PK11195 PET image acquisition sessions started immediately after the intravenous bolus injection of approximately $555 \mathrm{MBq}$ of ${ }^{11} \mathrm{C}-\mathrm{PiB}$ or 370 $\mathrm{MBq}$ of ${ }^{11} \mathrm{C}-\mathrm{PK} 11195$. To minimize head movement, the patient's head was restrained with a soft elastic tape. The PET images were reconstructed to a $128 \times 128 \times 90$ matrix, with $2 \mathrm{~mm}$ isotropic voxel dimension, using the LOR RAMLA algorithm (Philips PET/CT Gemini GXL) with attenuation and scatter correction.

\section{PET image pre-processing and quantitative analysis}

The PET image pre-processing and quantitative analysis pipeline was analogous for both type of PET data and was performed independently for the ${ }^{11} \mathrm{C}$ PiB PET and ${ }^{11} \mathrm{C}-\mathrm{PK} 11195$ PET sessions. Prior to pre-processing and quantitative analysis, the dynamic PET data used in this work were submitted to a frame-by-frame visual inspection to ensure that no coarse artifacts (e.g., related to radiotracer preparation, image acquisition and reconstruction, head motion) were present. In this work, given the sample size and the potential of confounding associations due to correlations between the GM volume and partial volume correction, we did not apply partial volume correction to the dynamic PET data. For each session, a sum image was obtained using all the frames of the dynamic PET. The sum image was used to estimate a rigid transformation between the ${ }^{11} \mathrm{C}-\mathrm{PiB}$ PET image space or ${ }^{11} \mathrm{C}$-PK11195 PET image space and the T1 anatomical MRI space of each participant. The rigid transformations were determined using 3D Slicer 4.8.1 (http://www.slicer.org) [43]. The individual MRI scans were spatially normalized to the to the Montreal Neurological Institute (MNI) template using DARTEL algorithm [41] in SPM12.

The voxel-level quantitative analysis of ${ }^{11} \mathrm{C}-\mathrm{PiB}$ PET images and ${ }^{11} \mathrm{C}-\mathrm{PK} 11195$ PET images was implemented in the MNI space using in-house made software. The individual ${ }^{11} \mathrm{C}-\mathrm{PiB}$ standard uptake value ratio (SUVR) map was computed by summing voxel-level signal from 40 to 70 min postinjection, and dividing by the mean signal from the individual's reference region, the cerebellar grey matter (essentially the cerebellum without the cerebellar peduncles) [44-46]. The individual ${ }^{11}$ C-PK11195 Binding Potential (BP) maps were generated using the MRTM2 (Multilinear Reference Tissue Model 2) [47]. The reference region was determined by the algorithm SVCA4 (Supervised Cluster Analysis with 4 classes: grey matter without specific binding, white matter, blood, grey matter with specific binding) [48] which selected a group of grey matter voxels showing a time-activity curve representing the kinetic activity of normal grey matter without ${ }^{11}$ C-PK11195 specific binding. The SUVR and BP maps were then transformed and resampled to the corresponding native MRI space using spatial transformations estimated in previous steps of the pipeline. Prior to SPM and BPM (see below) analysis PET datasets were smoothed with an $8 \times 8 \times 8 \mathrm{~mm}$ FWHM Gaussian filter.

\section{Statistical analysis}

A total of 20 mild stage AD patients and 17 matched HC were considered for both VBM-GM and ${ }^{11} \mathrm{C}-\mathrm{PiB}$ PET SUVR statistical parametric mapping analysis. For the ${ }^{11} \mathrm{C}-\mathrm{PK} 11195$ PET BP analysis only $19 \mathrm{AD}$ and $17 \mathrm{HC}$ were considered, since one $\mathrm{AD}$ patient gave up the exam.

After assessing for data normality using the Shapiro-Wilk test, $T$-test for unpaired samples or its non-parametric version, the Mann-Whitney test, were used for between-groups comparisons of the demographic and neuropsychological data. Fisher's Exact Test was used for comparing categorical variables (Sex). For the statistical analysis of these variables, we used IBM SPSS Statistics (version 22.0). The tests were performed two-tailed, and a threshold of $p<0.05$ was set for statistical significance.

In a first approach, in order to test whether GM volume, ${ }^{11} \mathrm{C}$-PK11195 BP and ${ }^{11} \mathrm{C}$-PiB SUVR were different between $\mathrm{AD}$ and $\mathrm{HC}$ groups we performed at voxel-level group comparisons by computing twosample $t$-tests in SPM12. For the VBM data, TIV (total intracranial volume) was used as a covariate to account for the difference in brain sizes.

Biological Parametric Mapping (BPM) [49], a MATLAB toolbox integrated in SPM5, was used to examine the local associations between GM volume, $A \beta$, and neuroinflammation. The BPM toolbox was used in MATLAB (version 7.12 (R2011a)). The BPM computes the General Linear Model (GLM) at each voxel and allows multiple regressions as either correlations tests between more than one 
imaging modality, while allowing for inclusion of non-imaging covariates. In a first step, we have computed an ANCOVA entering the VBM-GM images as the primary modality and the corresponding ${ }^{11} \mathrm{C}$ PiB SUVR images as the covariate image (imaging regressor). This analysis allowed testing for differences between $\mathrm{AD}$ and $\mathrm{HC}$ groups in grey-matter volumetric data (VBM-GM) controlling for differences in ${ }^{11} \mathrm{C}$-PiB SUVR data, and thus to detect the GM differences in AD that were not explained by between group differences in $A \beta$ levels. Secondly, we computed two multiple regression analysis in the AD group: 1) entering GM-VBM as the dependent variable and the corresponding ${ }^{11} \mathrm{C}-\mathrm{PiB}$ SUVR data as the imaging regressor, to investigate the effects of ${ }^{11} \mathrm{C}-\mathrm{PiB}$ SUVR levels on GM volume; 2) entering VBM-GM as the dependent variable and the corresponding ${ }^{11} \mathrm{C}-\mathrm{PK} 11195 \mathrm{BP}$ data as the imaging regressor, to investigate the regions where $\mathrm{GM}$ volume associated with microglia activation. We performed both regressions controlling for age and the presence of outliers (bi-square robust regression), and a GM mask (the average of all 20 AD subjects) was applied in order to remove any voxels that did not belong to the GM tissue, and thus limiting the problems with multiple comparisons. Posteriorly, we have repeated the same regression analysis but merging both groups (17 HC and $20 \mathrm{AD}$ ).

In addition, the correlation between the ${ }^{11} \mathrm{C}-\mathrm{PiB}$ SUVR images and ${ }^{11}$ C-PK11195 BP images was calculated on a voxel-by-voxel basis with the BPM correlation design in the $\mathrm{AD}$ group, in order to examine the regions showing associations between both pathological molecular measures.

Moreover, we have also complemented the whole brain voxel-by-voxel analysis with the more sensitive analysis at the ROI level. Firstly, we investigate associations between VBM-GM and ${ }^{11}$ C-PK11195 BP data, and between ${ }^{11} \mathrm{C}$-PiB PET and ${ }^{11} \mathrm{C}$-PK11195 PET data in the regions that revealed microglia activation in AD patients, in order to examine associations between GM and microglia, and between the latter and $A \beta$ load in these regions. As such, the clusters that revealed higher microglia activation in $\mathrm{AD}$ were used to define masks that were then applied to extract the regional mean values of ${ }^{11} \mathrm{C}-\mathrm{PiB}$ SUVR, VBM-GM, and ${ }^{11} \mathrm{C}-\mathrm{PK} 11195 \mathrm{BP}$ in AD subjects.

Secondly, we performed ROI-based correlation tests in a set of anatomically defined regions from the AAL (Automated Anatomical Labeling) atlas [50] for right and left hemispheres individually namely: frontal superior, frontal middle, frontal inferior orbital, insula, cingulum anterior, cingulum posterior, hippocampus, parahippocampal, amygdala, lingual, occipital middle, occipital inferior, fusiform, parietal inferior, angular, precuneus, temporal superior, temporal middle, temporal inferior regions. We have extracted for each ROI the mean values of each data modality: ${ }^{11} \mathrm{C}-\mathrm{PiB}$ SUVR, VBM-GM, and ${ }^{11} \mathrm{C}$ PK11195 BP, to each AD patient in MRI native space. Given the normal distribution of the data, as assessed by the Shapiro-Wilk test, Pearson correlation tests were computed between VBM-GM and ${ }^{11} \mathrm{C}-\mathrm{PiB}$ SUVR, VBM-GM, and ${ }^{11} \mathrm{C}-\mathrm{PK} 11195 \mathrm{BP}$, and between ${ }^{11} \mathrm{C}-\mathrm{PiB}$ SUVR and ${ }^{11} \mathrm{C}-\mathrm{PK} 11195 \mathrm{BP}$ in each ROI. We conducted this analysis in IBM SPSS Statistics (version 22.0).

The distinct statistical power of each image modality prevented us to use the same statistical thresholds levels across the various voxel-wise analysis. For example, the signal relative to ${ }^{11} \mathrm{C}-\mathrm{PK} 11195$ PET uptake is lower than the signal of ${ }^{11} \mathrm{C}$-PiB PET uptake, resulting in part from the lower density of activated microglia with regard to $A \beta$ plaques, and also due to the lower signal to-noise ratio of ${ }^{11} \mathrm{C}$-PK11195 PET tracer. Thus, we were more liberal regarding the statistical thresholds for the ${ }^{11} \mathrm{C}$ PK11195 PET data analysis, to prevent Type II errors. Nonetheless, the statistical thresholds used are in line with the literature, we opted by thresholds that let us prevent the above-mentioned type of error and being too conservative.

The resulting statistical T-maps and the correspondent unthresholded effect size (Cohen's d) maps determined using CAT12 toolbox, were overlaid on the T1-weighted template in the axial plane.

\section{RESULTS}

Concerning the demographic data, no evidence of a difference in age, sex or education was found between groups but, as expected, a significant difference was found regarding MoCA scores (Table 1).

\section{$V B M$}

For the between-groups comparisons of VBM data we used a voxel-wise statistical threshold of $p<0.005$, false discovery rate corrected (FDR), with and extent threshold of 100 voxels. The resulting clusters were considered significant using a statistical threshold of $p<0.05$ (FDR corrected, cluster level). Results show, as expected, a significant diffuse pattern of volume loss in AD brains (Fig. 1). Evident GM atrophy was seen in regions known preferentially 
affected in the disease, as following: middle and inferior temporal areas, regions from the medial temporal lobe and cingulate areas. Information about the significant peak points, number of voxels and respective $p$-value as well as MNI coordinates are provided in Table 2.

\section{${ }^{11} C-P i B$ PET}

$\mathrm{A} \beta$ load differences in parametric ${ }^{11} \mathrm{C}-\mathrm{PiB}$ SUVR images were localized, using a statistical threshold

Table 1

Demographics features of all participants

\begin{tabular}{lccc}
\hline & $\begin{array}{c}\text { AD group } \\
(n=20) \\
(\text { mean } \pm \mathrm{SD})\end{array}$ & $\begin{array}{c}\text { HC group } \\
(n=17) \\
(\text { mean } \pm \mathrm{SD})\end{array}$ & $p$ \\
\hline Age & $66.25(6.87)$ & $65.24(7.00)$ & 0.66 \\
Female/male ratio & $10 / 10$ & $8 / 9$ & 1.00 \\
Education & $9.30(5.93)$ & $11.59(5.82)$ & 0.26 \\
MMSE & $23.1(2.97)$ & - & \\
MoCA & $14.26(4.31)$ & $24.94(3.62)$ & $<0.001$ \\
CDR & 1 & - & \\
\hline
\end{tabular}

$\mathrm{AD}$, patients with Alzheimer's disease; HC, healthy controls; SD, standard deviation; MMSE, Mini-Mental State Examination; MoCA, Montreal cognitive assessment; CDR, Clinical Dementia Rating; Data are expressed as mean $\pm \mathrm{SD}$, except for female/male ratio.
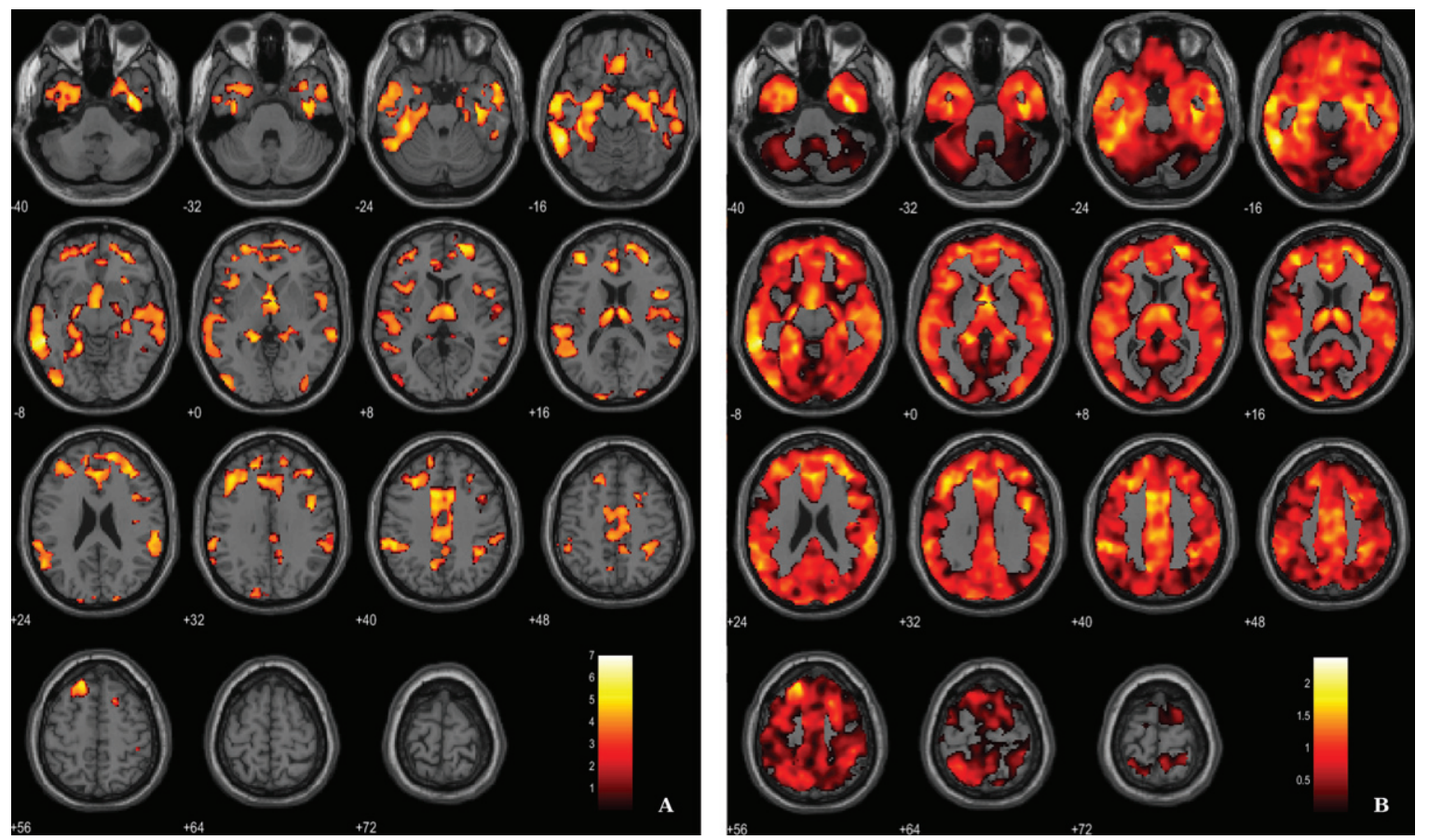

Fig. 1. Voxel-based between-group comparison of GM maps superimposed on the T1-weighted template in the axial plane for the AD $<\mathrm{HC}$ contrast. A) Thresholded T-map ( $p<0.005$, FDR corrected at voxel-level, cluster size $>100$ voxels). B) Unthresholded effect size (Cohen's d) map. 
Table 2

Regions of significantly reduced GM volume in AD patients compared to $\mathrm{HC}$

\begin{tabular}{|c|c|c|c|c|c|c|}
\hline \multirow[t]{2}{*}{ Region } & \multirow[t]{2}{*}{ Cluster size } & \multicolumn{3}{|c|}{ MNI coordinates } & \multirow[t]{2}{*}{$\mathrm{T}$ value } & \multirow[t]{2}{*}{$\overline{\text { Cohen's d }}$} \\
\hline & & $\mathrm{X}$ & $\mathrm{Y}$ & $\mathrm{Z}$ & & \\
\hline \multirow[t]{3}{*}{ Lateral temporal lobe (BA21) } & 20273 & -54 & -41 & -9 & 7.00 & 2.40 \\
\hline & & -38 & -33 & -21 & 6.07 & 2.08 \\
\hline & & -50 & -38 & 42 & 5.63 & 1.93 \\
\hline \multirow{3}{*}{ Inferior temporal lobe (BA20) } & 15418 & 36 & -3 & -39 & 6.67 & 2.29 \\
\hline & & 39 & -21 & -23 & 5.53 & 1.90 \\
\hline & & 44 & 3 & 30 & 5.44 & 1.86 \\
\hline \multirow[t]{3}{*}{ Dorsal anterior cingulate (BA32) } & 16492 & -8 & 12 & 42 & 5.90 & 2.02 \\
\hline & & 20 & 56 & 8 & 5.80 & 1.99 \\
\hline & & -15 & 32 & 56 & 5.77 & 1.98 \\
\hline \multirow[t]{2}{*}{ Occipital lobe (BA19) } & 1144 & -42 & -83 & -5 & 5.51 & 1.89 \\
\hline & & -44 & -89 & 6 & 4.11 & 1.41 \\
\hline \multirow[t]{3}{*}{ Thalamus } & 3506 & -5 & 2 & -2 & 5.47 & 1.88 \\
\hline & & 6 & -11 & 14 & 5.29 & 1.82 \\
\hline & & -5 & -11 & 14 & 5.12 & 1.76 \\
\hline \multirow{3}{*}{ Frontal lobe (BA6) } & 373 & 18 & 12 & 51 & 5.19 & 1.78 \\
\hline & & 30 & 17 & 45 & 4.54 & 1.56 \\
\hline & & 27 & 3 & 51 & 3.78 & 1.30 \\
\hline \multirow[t]{3}{*}{ Angular gyrus (BA39) } & 768 & 38 & -47 & 38 & 5.10 & 1.75 \\
\hline & & 32 & -41 & 48 & 4.80 & 1.65 \\
\hline & & 42 & -36 & 51 & 4.38 & 1.50 \\
\hline \multirow[t]{2}{*}{ Isthmus of cingulate gyrus (BA31) } & 279 & -9 & -62 & 41 & 4.81 & 1.65 \\
\hline & & 0 & -56 & 41 & 3.69 & 1.27 \\
\hline \multirow[t]{3}{*}{ Visual associative cortex (BA18) } & 278 & -12 & -102 & 17 & 4.50 & 1.54 \\
\hline & & -6 & -96 & 20 & 3.86 & 1.33 \\
\hline & & -2 & -93 & 26 & 3.52 & 1.24 \\
\hline Insula (BA13) & 113 & 29 & 21 & -8 & 4.49 & 1.54 \\
\hline \multirow[t]{3}{*}{ Insula (BA13) } & 809 & -38 & 21 & -2 & 4.47 & 1.53 \\
\hline & & -41 & 14 & 5 & 4.31 & 1.48 \\
\hline & & -48 & 18 & 6 & 4.13 & 1.42 \\
\hline \multirow[t]{3}{*}{ Visual associative cortex (BA18) } & 567 & 26 & -99 & 15 & 4.16 & 1.43 \\
\hline & & 41 & -80 & 3 & 4.05 & 1.39 \\
\hline & & 21 & -96 & 23 & 4.01 & 1.37 \\
\hline Insula (BA13) & 108 & -35 & -9 & 12 & 4.05 & 1.39 \\
\hline Occipital lobe (BA19) & 115 & -15 & -90 & 33 & 4.02 & 1.38 \\
\hline
\end{tabular}

BA, Broadman areas; clusters were considered significant using a voxel-wise statistical threshold of $p<0.005$ (FDR corrected for multiple comparisons) with an extent threshold of 100 voxels.

parahippocampal gyrus and cingulate gyrus. Table 3 and Fig. 3 depict significant clusters.

\section{BPM analysis}

For the ANCOVA design, the ${ }^{11} \mathrm{C}-\mathrm{PiB}$ SUVR images were inserted as explanatory variables to evaluate the influence of $A \beta$ levels differences in the structural integrity (VBM-GM data). A voxelwise statistical threshold of $p<0.03$ (FDR corrected) and a cluster extent of 60 voxels were considered. Results revealed that apparently ${ }^{11} \mathrm{C}-\mathrm{PiB}$ SUVR did not account for GM differences in some regions such as medial temporal lobe, thalamus, prefrontal cortex and superior parietal cortex, among other regions (Table 4 and Fig. 4).
Results from the regression analysis between VBM-GM data and ${ }^{11} \mathrm{C}$-PiB SUVR images in the AD group have revealed weak associations between the two image modalities in fusiform gyrus, lateral temporal lobe and parietal lobe (Fig. 5, Table 5). We used a voxel-wise threshold of $p<0.001$ (uncorrected, except for the extent cluster correction threshold of 40 voxels).

In addition, following an approach replicating previous studies [51, 52] we have merged both groups in order to search for associations between VBM-GM and $A \beta$ data. For the regression between the VBMGM and ${ }^{11} \mathrm{C}-\mathrm{PiB}$ SUVR data, aggregating $20 \mathrm{AD}$ and $17 \mathrm{HC}$, we used a voxel-wise threshold of $p<0.03$ (FDR corrected) with an extent threshold of 60 voxels. The results evidence stronger associations when 

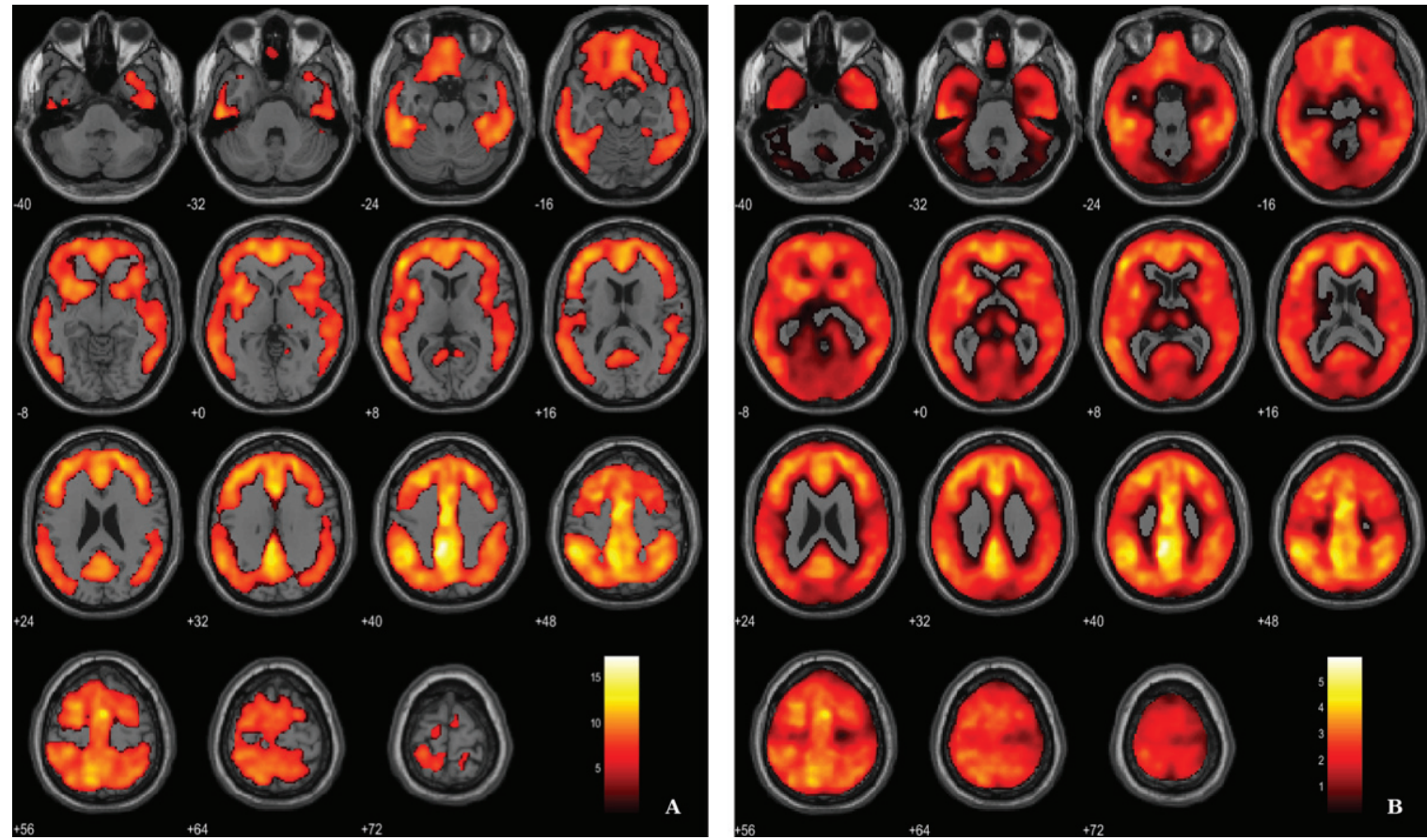

Fig. 2. Voxel-based between-group comparison of ${ }^{11} \mathrm{C}$-PiB PET SUVR maps superimposed on the T1-weighted template in the axial plane for the AD $>$ HC contrast. A) Thresholded T-map ( $p<0.01$, FWE-corrected at voxel-level, cluster size $>100$ voxels). B) Unthresholded effect size (Cohen's d) map.

Table 3

Regions of significant elevated ${ }^{11} \mathrm{C}-\mathrm{PK} 11195 \mathrm{BP}$ in patients with AD compared to HC

\begin{tabular}{|c|c|c|c|c|c|c|}
\hline \multirow[t]{2}{*}{ Region } & \multirow[t]{2}{*}{ Cluster size } & \multicolumn{3}{|c|}{ MNI coordinates } & \multirow[t]{2}{*}{ T value } & \multirow[t]{2}{*}{$\overline{\text { Cohen's d }}$} \\
\hline & & $\mathrm{X}$ & $\mathrm{Y}$ & $\mathrm{Z}$ & & \\
\hline \multirow[t]{2}{*}{ Parahippocampal gyrus (BA36) } & 216 & -16 & 2 & -36 & 5.03 & 1.73 \\
\hline & & -32 & 10 & -40 & 3.03 & 1.04 \\
\hline \multirow[t]{3}{*}{ Isthmus of cingulate gyrus (BA31) } & 3059 & -2 & -46 & 52 & 4.94 & 1.70 \\
\hline & & -10 & -42 & 42 & 4.88 & 1.67 \\
\hline & & -30 & -55 & 38 & 4.02 & 0.61 \\
\hline Isthmus of cingulate gyrus (BA31) & 267 & 16 & -62 & 28 & 4.47 & 1.53 \\
\hline Posterior cingulate cortex (BA23) & 126 & 8 & -44 & 30 & 4.06 & 1.39 \\
\hline \multirow{2}{*}{ Superior frontal gyrus (BA6) } & 183 & 12 & -8 & 70 & 4.00 & 1.37 \\
\hline & & 12 & -26 & 70 & 2.95 & 1.01 \\
\hline \multirow[t]{3}{*}{ Superior frontal gyrus (BA8) } & 253 & 18 & 36 & 46 & 3.94 & 1.35 \\
\hline & & 8 & 42 & 46 & 3.20 & 1.10 \\
\hline & & 8 & 32 & 52 & 3.17 & 1.09 \\
\hline \multirow[t]{3}{*}{ Dorsal anterior cingulate (BA32) } & 393 & -8 & 8 & 44 & 3.79 & 1.30 \\
\hline & & -25 & 18 & 42 & 3.57 & 1.19 \\
\hline & & -4 & 0 & 74 & 3.12 & 1.07 \\
\hline \multirow{3}{*}{ Inferior frontal lobe (BA44) } & 162 & 52 & 20 & 20 & 3.48 & 1.19 \\
\hline & & 56 & 10 & 20 & 3.42 & 1.17 \\
\hline & & 40 & 20 & 22 & 2.80 & 0.96 \\
\hline Parahippocampal gyrus (BA36) & 136 & 16 & -10 & -34 & 3.35 & 1.15 \\
\hline \multirow[t]{2}{*}{ Lateral temporal lobe (BA21) } & 161 & -54 & -34 & -8 & 3.33 & 1.14 \\
\hline & & -60 & -38 & -16 & 3.26 & 1.12 \\
\hline \multirow[t]{3}{*}{ Middle frontal gyrus (BA6) } & 119 & 24 & 14 & 46 & 3.26 & 1.12 \\
\hline & & 22 & 10 & 62 & 2.83 & 0.97 \\
\hline & & 32 & 6 & 60 & 2.69 & 0.92 \\
\hline
\end{tabular}

BA, Broadman areas; clusters were considered significant using a voxel-wise statistical threshold of $p<0.01$ (uncorrected) with an extent threshold of 100 voxels. 

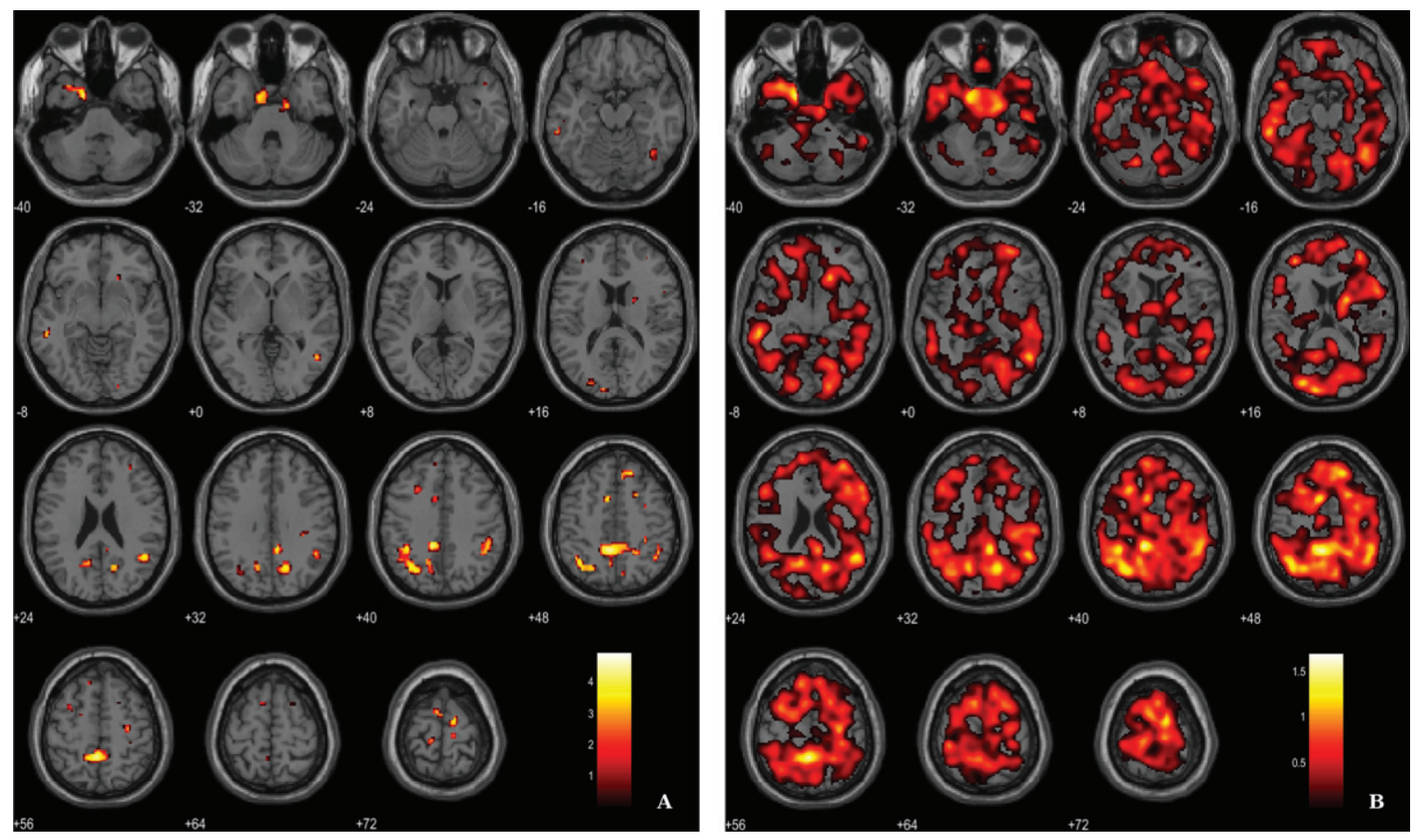

Fig. 3. Voxel-based between-group comparison of ${ }^{11} \mathrm{C}-\mathrm{PK} 11195 \mathrm{BP}$ maps superimposed on the T1-weighted template in the axial plane for the AD $>$ HC contrast. A) Thresholded T-map ( $p<0.01$, uncorrected at voxel-level, cluster size $>100$ voxels). B) Unthresholded effect size (Cohen's d) map.

compared to the AD group solo, surviving to a more demanding statistical threshold (Fig. 6; Table 6).

In addition, results from the regression analysis between VBM-GM data and ${ }^{11} \mathrm{C}-\mathrm{PK} 11195 \mathrm{BP}$ data in the $\mathrm{AD}$ group did not reveal significant associations between GM volume and neuroinflammation in the less sensitive voxel-wise analysis.

Likewise, the voxel-to-voxel correlation analysis between ${ }^{11} \mathrm{C}-\mathrm{PiB}$ SUVR images and ${ }^{11} \mathrm{C}-\mathrm{PK} 11195$ $\mathrm{BP}$ data did not show significant relationships between the two molecular imaging markers. This suggested to follow a more sensitive approach, based on ROI analysis.

\section{ROI-based analysis}

Since no significant associations were found when considering neuroinflammation data in a voxel-wise fashion, we opted to carry out region-based correlation analysis in the areas that showed significant microglia activation in AD. Results evidence a modest negative correlation between VBM-GM data and ${ }^{11} \mathrm{C}-\mathrm{PK} 11195 \mathrm{BP}$ data in lateral temporal lobe (BA21) of AD group $(r=-0.526, p=0.021)$ and a positive correlation between ${ }^{11} \mathrm{C}-\mathrm{PiB}$ SUVR and ${ }^{11} \mathrm{C}$ PK11195 BP in right superior frontal gyrus (BA8) $(r=0.523, p=0.019)$.
The results from tests in anatomic ROIs unveiled some associations between pairs of neuropathological markers: a negative association between GM volume and ${ }^{11} \mathrm{C}$-PiB SUVR in left angular region $(r=-0.514, p=0.021)$ and left middle temporal region $(r=-0.562, p=0.010)$, a week negative correlation between VBM and ${ }^{11} \mathrm{C}-\mathrm{PK} 11195 \mathrm{BP}$ in left middle frontal $(r=-0.457, p<0.049)$ and in left inferior temporal cortex $(r=-0.457, p<0.049)$. In contrast, a stronger positive association between VBM and ${ }^{11}$ C-PK11195 BP was found in left hippocampus $(r=0.810, p<0.001)$, right hippocampus $(r=0.614, p=0.005)$ and left parahippocampal region $(p=0.557, p=0.013)$. Finally, associations between ${ }^{11} \mathrm{C}$-PiB SUVR and ${ }^{11} \mathrm{C}-\mathrm{PK} 11195 \mathrm{BP}$ were found only in left hippocampus $(r=0.629, p=0.004)$. These ROI-based results are exploratory and therefore were not corrected for multiple comparisons.

Overall, our results suggest that $A \beta$ deposition is more tightly linked to brain atrophy than neuroinflammation.

\section{DISCUSSION}

It has been considered that $\mathrm{A} \beta$ accumulation triggers neurotoxic events in $\mathrm{AD}$ [53] leading to 
Table 4

Results from ANCOVA reflecting regions where VBM-GM differences were not explained by ${ }^{11} \mathrm{C}-\mathrm{PiB}$ SUVR levels in AD

\begin{tabular}{|c|c|c|c|c|c|c|}
\hline \multirow[t]{2}{*}{ Region } & \multirow[t]{2}{*}{ Cluster size } & \multicolumn{3}{|c|}{ MNI coordinates } & \multirow[t]{2}{*}{ T value } & \multirow[t]{2}{*}{ Cohen's d } \\
\hline & & $\mathrm{X}$ & $\mathrm{Y}$ & $\mathrm{Z}$ & & \\
\hline \multirow[t]{3}{*}{ Amygdala/Parahippocampal gyrus (BA36) } & 3594 & -21 & 9 & -27 & 7.76 & 2.70 \\
\hline & & -38 & -33 & -17 & 6.13 & 2.13 \\
\hline & & -24 & 15 & -23 & 5.93 & 2.06 \\
\hline \multirow[t]{3}{*}{ Thalamus } & 2697 & -5 & -15 & 8 & 6.87 & 2.39 \\
\hline & & 12 & -15 & 12 & 5.65 & 1.97 \\
\hline & & -5 & 3 & -2 & 5.50 & 1.91 \\
\hline \multirow[t]{3}{*}{ Hippocampus } & 1380 & 38 & -17 & -21 & 5.95 & 2.07 \\
\hline & & 39 & -26 & -17 & 5.52 & 1.92 \\
\hline & & 21 & -9 & -17 & 5.37 & 1.87 \\
\hline \multirow[t]{3}{*}{ Frontal lobe (BA47) } & 297 & 33 & 48 & -9 & 5.59 & 1.95 \\
\hline & & 36 & 39 & -14 & 4.81 & 1.68 \\
\hline & & 27 & 38 & -15 & 3.67 & 1.28 \\
\hline \multirow[t]{3}{*}{ Prefrontal cortex (BA10) } & 1025 & 29 & 60 & 8 & 5.51 & 1.92 \\
\hline & & 14 & 68 & 5 & 5.19 & 1.81 \\
\hline & & 23 & 62 & 14 & 5.03 & 1.75 \\
\hline Fusiform gyrus (BA37) & 71 & -50 & -51 & -27 & 5.33 & 1.86 \\
\hline Prefrontal cortex (BA10) & 120 & -44 & 50 & 17 & 5.24 & 1.82 \\
\hline \multirow[t]{2}{*}{ Prefrontal cortex (BA10) } & 163 & -30 & 62 & 0 & 4.94 & 1.72 \\
\hline & & -33 & 60 & 8 & 4.51 & 1.57 \\
\hline \multirow[t]{2}{*}{ Superior parietal cortex (BA7) } & 185 & 0 & -63 & 51 & 4.80 & 1.67 \\
\hline & & -3 & -65 & 60 & 3.60 & 1.25 \\
\hline Prefrontal cortex (BA11) & 165 & -18 & 29 & -20 & 4.79 & 1.67 \\
\hline Superior parietal cortex (BA7) & 90 & -3 & -77 & 41 & 4.72 & 1.64 \\
\hline Superior parietal cortex (BA7) & 95 & 35 & -44 & 51 & 4.49 & 1.56 \\
\hline Visual associative cortex (BA18) & 139 & 14 & -41 & 0 & 4.43 & 1.54 \\
\hline \multirow[t]{2}{*}{ Prefrontal cortex (BA11) } & 135 & 17 & 20 & -23 & 4.41 & 1.53 \\
\hline & & 17 & 30 & -18 & 3.46 & 1.20 \\
\hline Parietal cortex (BA40) & 63 & -45 & -48 & 57 & 4.35 & 1.51 \\
\hline \multirow[t]{3}{*}{ Superior temporal gyrus (BA22) } & 111 & 51 & 6 & -2 & 4.31 & 1.50 \\
\hline & & 50 & 14 & -6 & 4.04 & 1.41 \\
\hline & & 54 & 14 & 3 & 3.71 & 1.29 \\
\hline Frontal cortex (BA6) & 710 & -3 & 21 & 62 & 4.31 & 1.50 \\
\hline
\end{tabular}

BA, Broadman areas; clusters were considered significant using a voxel-wise statistical threshold of $p<0.03$ (FDR corrected for multiple comparisons) with an extent threshold of 60 voxels.

brain atrophy, where neuroinflammation may play an important role. Nevertheless, the relationships between these neuropathological events and their dynamics along disease trajectories remain far from certain. In the present study we found a significant interplay between $A \beta$ and atrophy but a less prominent and more restricted interplay between neuroinflammation and atrophy in early AD.

Regarding the ${ }^{11} \mathrm{C}-\mathrm{PiB}$ PET retention, our results from the between group comparisons are in line with the pattern reported in the literature $[20,23,28,54$, 55]. Also, VBM results confirmed a pattern of atrophy already reported in previous studies performed with subjects in early stages of AD [56-59]. However, studies combining $A \beta$ and GM have reported incongruent results concerning the relationships between both [21, 51, 60, 61].

At early stages of the disease $(\mathrm{CDR}=1)$ we found some regions where structural neurodegeneration appeared independent of $\mathrm{A} \beta$ deposition in some areas, namely medial temporal areas (amygdala, hippocampus), frontal, prefrontal, superior parietal and occipital. In particular, medial temporal areas, including hippocampus and amygdala, have shown the lowest or absent $A \beta$ deposition in imaging studies $[23,28,54,62,63]$, despite being highly susceptible to GM loss and the earliest regions to degenerate [58, 64-68]. In fact, it has been suggested that the presence of neurofibrillary tangles, rather than $A \beta$ might account for atrophy in these regions [57-62]. Moreover, the deposition of soluble $A \beta$ species, the most toxic form [69], that are not sensed by current PET imaging might explain degeneration in these regions [70-73]. In turn, a distant effect of $A \beta$ on the hippocampus was also reported [74].

In opposition, frontal areas are the ones that show higher and earlier $A \beta$ deposition $[20,23,28,54,62$, 63] but the last to experience atrophy [58, 64-68]. 

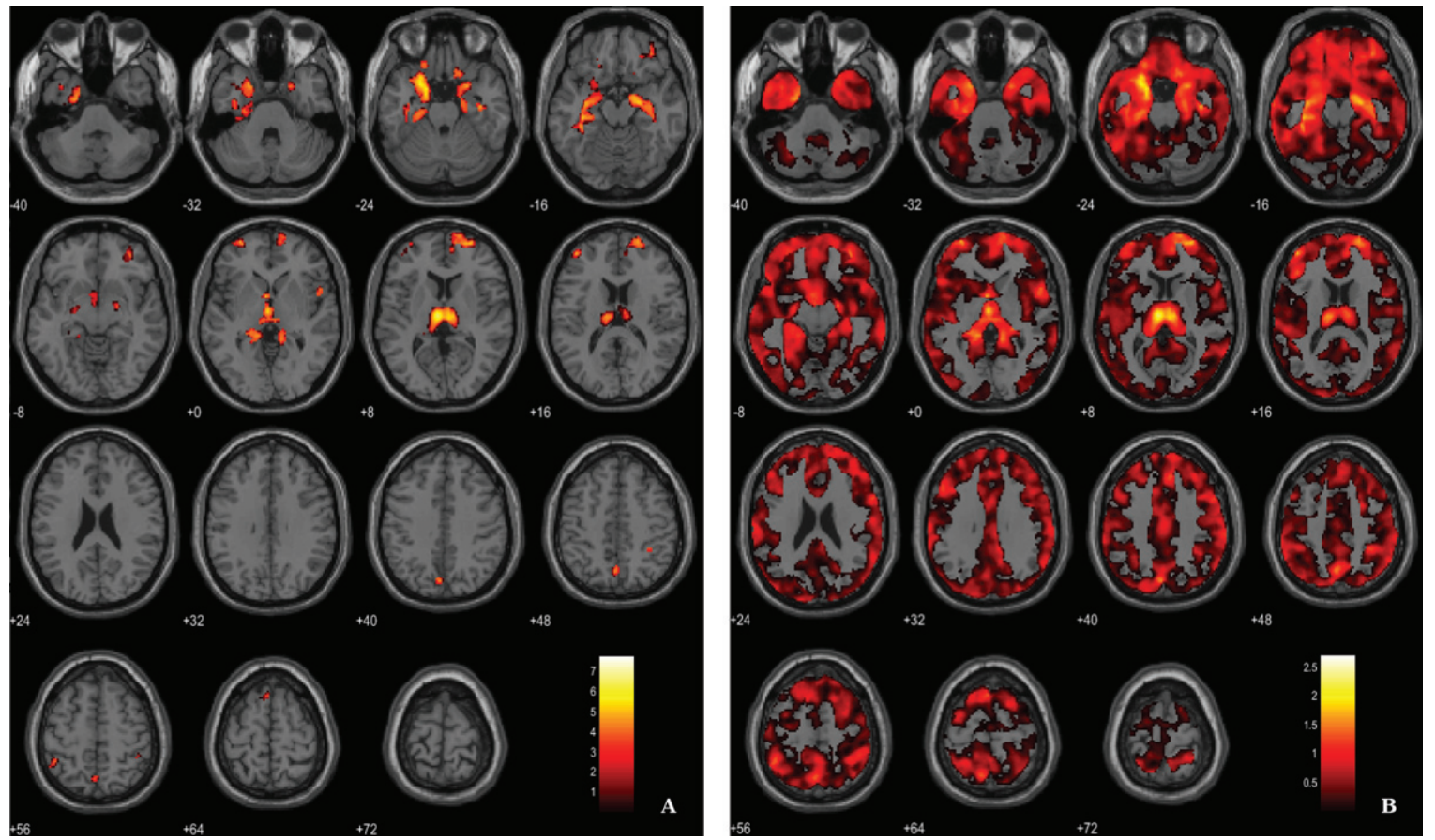

Fig. 4. BPM ANCOVA analysis of GM maps superimposed on the T1-weighted template in the axial plane for the contrast $\mathrm{AD}<\mathrm{CT}$ and controlling for ${ }^{11} \mathrm{C}-\mathrm{PiB}$ SUVR levels. A) Thresholded T-map $(p<0.03$, FDR corrected at voxel-level, cluster size $>60$ voxels). B) Unthresholded effect size (Cohen's d) map.
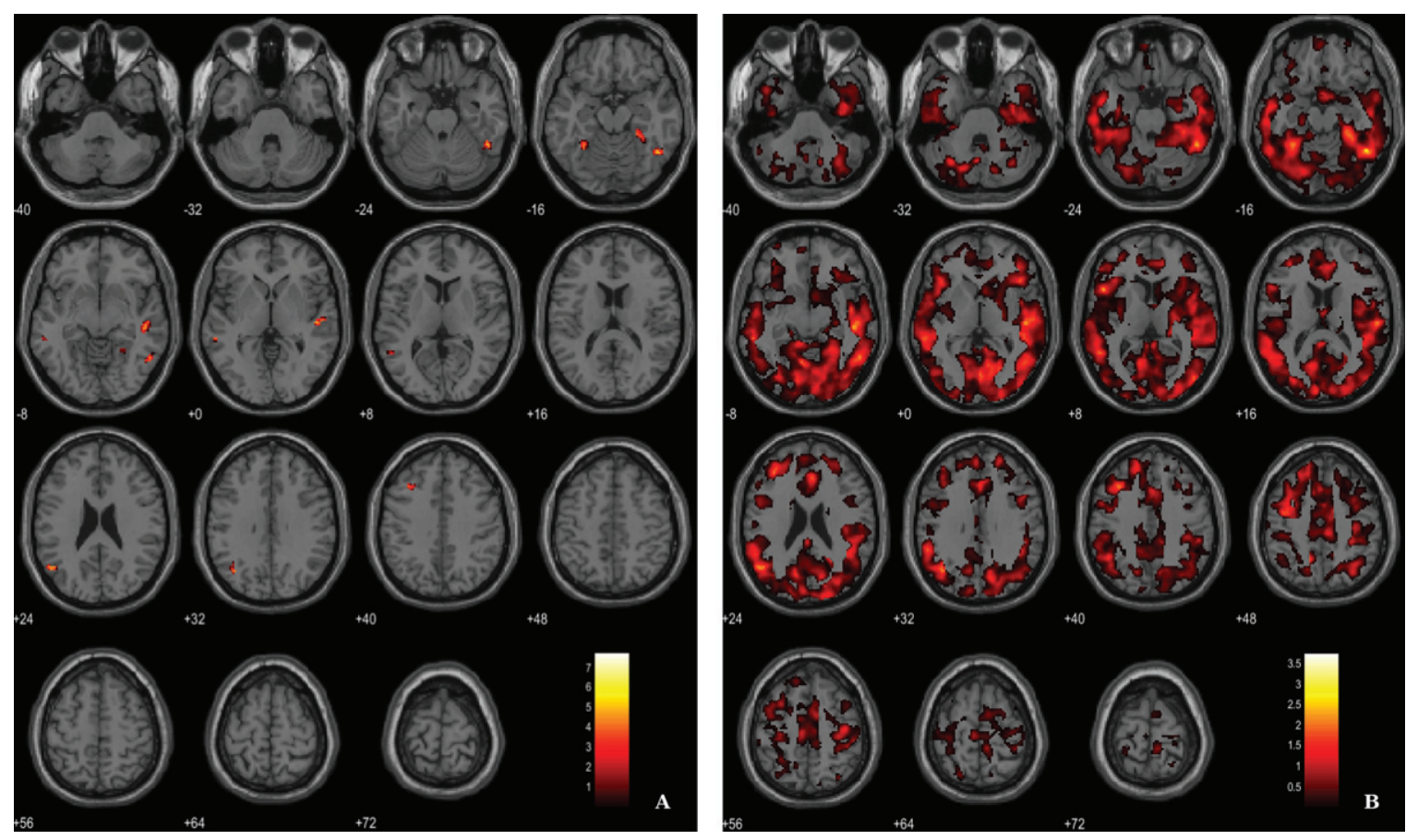

Fig. 5. BPM regression analysis between VBM-GM and ${ }^{11} \mathrm{C}-\mathrm{PiB}$ SUVR maps for the AD group superimposed on the T1-weighted template in the axial plane. A) Thresholded T-map ( $p<0.001$, cluster size $>40$ voxels). B) Unthresholded effect size (Cohen's d) map. 
Table 5

Regions of significant association between VBM-GM and ${ }^{11} \mathrm{C}-\mathrm{PiB}$ SUVR in AD patients

\begin{tabular}{|c|c|c|c|c|c|c|}
\hline \multirow[t]{2}{*}{ Region } & \multirow[t]{2}{*}{ Cluster size } & \multicolumn{3}{|c|}{ MNI coordinates } & \multirow[t]{2}{*}{ T value } & \multirow[t]{2}{*}{ Cohen's d } \\
\hline & & $\mathrm{X}$ & $\mathrm{Y}$ & $\mathrm{Z}$ & & \\
\hline \multirow[t]{3}{*}{ Fusiform gyrus (BA37) } & 221 & 47 & -54 & -17 & 7.73 & 3.75 \\
\hline & & 51 & -48 & -26 & 5.42 & 2.63 \\
\hline & & 54 & -56 & -8 & 4.62 & 2.24 \\
\hline \multirow[t]{2}{*}{ Lateral temporal lobe (BA21) } & 209 & 51 & -21 & 2 & 6.15 & 2.98 \\
\hline & & 48 & -26 & -6 & 5.73 & 2.78 \\
\hline Frontal lobe (BA8) & 59 & -35 & 21 & 44 & 6.05 & 2.94 \\
\hline \multirow[t]{2}{*}{ Angular gyrus (BA39) } & 136 & -51 & -63 & 23 & 5.41 & 2.63 \\
\hline & & -39 & -63 & 32 & 4.80 & 2.33 \\
\hline \multirow[t]{3}{*}{ Fusiform gyrus (BA37) } & 150 & 27 & -33 & -18 & 4.91 & 2.38 \\
\hline & & 33 & -48 & -12 & 4.71 & 2.29 \\
\hline & & 24 & -48 & -11 & 4.29 & 2.08 \\
\hline Lateral temporal lobe (BA21) & 61 & -57 & -39 & -6 & 4.76 & 2.31 \\
\hline
\end{tabular}

BA, Broadman areas; clusters were considered significant using a voxel-wise statistical threshold of $p<0.001$ (uncorrected) with an extent threshold of 40 voxels.
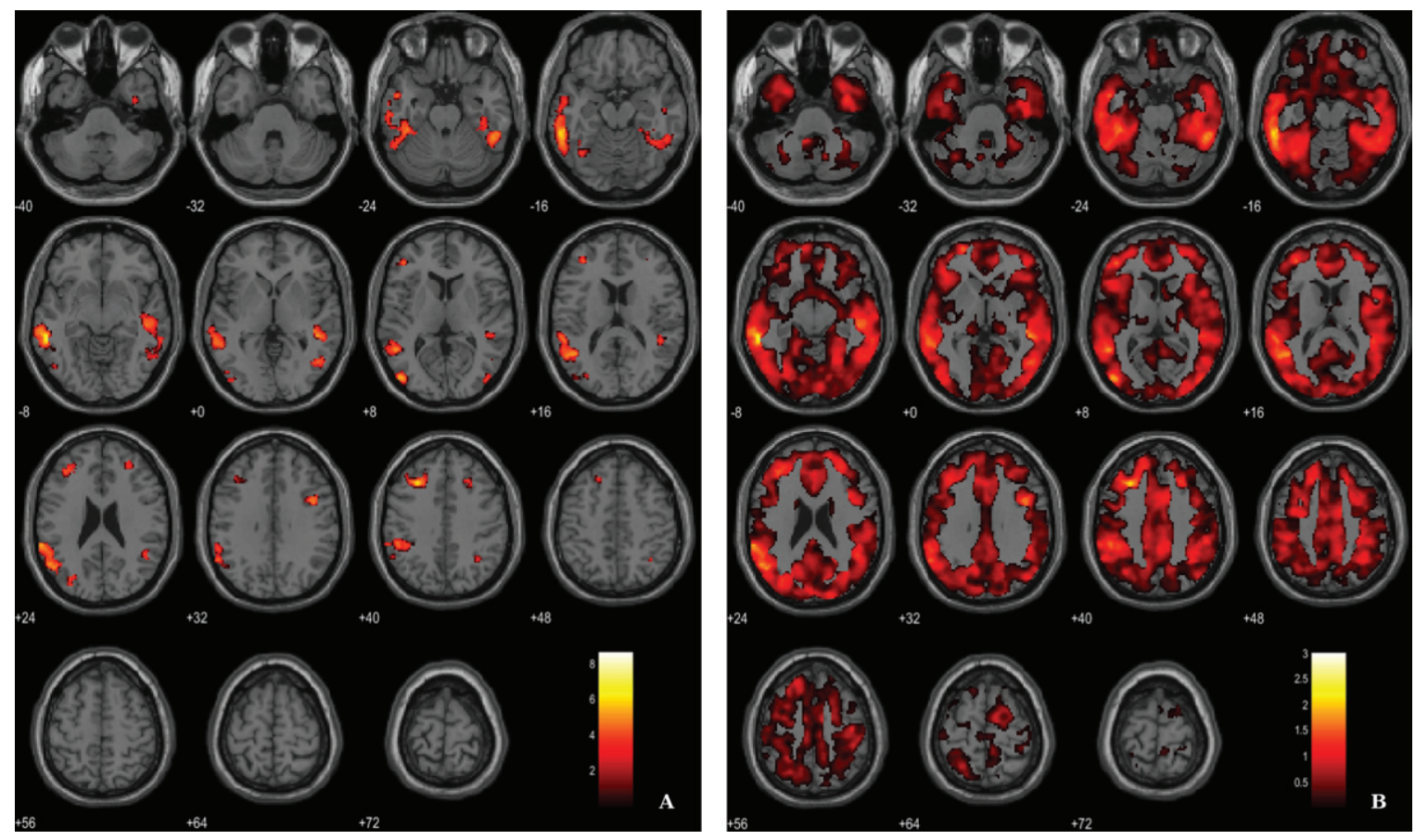

Fig. 6. BPM regression analysis between VBM-GM and ${ }^{11} \mathrm{C}-\mathrm{PiB}$ SUVR maps for $20 \mathrm{AD}$ and $17 \mathrm{HC}$ superimposed on the T1-weighted template in the axial plane. A) Thresholded T-map ( $p<0.03$, FDR corrected at voxel-level, cluster size $>60)$. B) Unthresholded effect size (Cohen's d) map.

In fact, this resilience of frontal cortex to atrophy may arise from compensatory mechanisms (for a review, see [75]) namely compensatory changes in neurotransmitter systems [76, 77]. It is also possible that a higher synaptic/dendritic density present in frontal areas [78] delay the neurotoxicity of $A \beta$ maintaining brain volume for longer. A significant independence of $A \beta$ and atrophy in thalamus and occipital cortex have also stood out, two regions characterized by the lowest $\mathrm{A} \beta$ uptake levels in PET imaging studies $[23,79]$.

On the other hand, the regression analysis between ${ }^{11} \mathrm{C}-\mathrm{PiB}$ PET and VBM data in the $20 \mathrm{AD}$ patients revealed modest associations between both in fusiform gyrus, lateral temporal lobe, and angular gyrus, areas highly implicated in this early stage of the disease. Similarly, it was observed in early AD that $\mathrm{A} \beta$ was related to cortical thickness reductions 
Table 6

Regions of significant association between VBM-GM and ${ }^{11} \mathrm{C}-\mathrm{PiB}$ SUVR in AD patients and HC

\begin{tabular}{|c|c|c|c|c|c|c|}
\hline \multirow[t]{2}{*}{ Region } & \multirow[t]{2}{*}{ Cluster size } & \multicolumn{3}{|c|}{ MNI coordinates } & \multirow[t]{2}{*}{ T value } & \multirow[t]{2}{*}{$\overline{\text { Cohen's d }}$} \\
\hline & & $\mathrm{X}$ & $\mathrm{Y}$ & $\mathrm{Z}$ & & \\
\hline \multirow[t]{3}{*}{ Lateral temporal lobe (BA21) } & 6652 & -57 & -41 & -6 & 8.66 & 3.02 \\
\hline & & -59 & -36 & -14 & 7.01 & 2.44 \\
\hline & & -63 & -39 & 23 & 6.18 & 2.15 \\
\hline \multirow[t]{3}{*}{ Prefrontal cortex (BA9) } & 1015 & -29 & 26 & 41 & 6.68 & 2.32 \\
\hline & & -42 & 39 & 8 & 5.00 & 1.74 \\
\hline & & -38 & 39 & 23 & 4.80 & 1.67 \\
\hline \multirow[t]{2}{*}{ Occipital lobe (BA19) } & 455 & -44 & -81 & 6 & 5.96 & 2.07 \\
\hline & & -47 & -71 & -5 & 4.23 & 1.47 \\
\hline \multirow[t]{3}{*}{ Lateral temporal lobe (BA21) } & 3024 & 48 & -38 & -2 & 5.67 & 1.98 \\
\hline & & 51 & -45 & -26 & 5.32 & 1.85 \\
\hline & & 47 & -27 & -6 & 5.30 & 1.84 \\
\hline Frontal cortex (BA6) & 274 & 41 & 8 & 33 & 5.61 & 1.95 \\
\hline \multirow[t]{3}{*}{ Occipital lobe (BA19) } & 214 & -32 & -78 & 18 & 4.88 & 1.70 \\
\hline & & -24 & -84 & 20 & 4.08 & 1.42 \\
\hline & & -27 & -72 & 23 & 3.75 & 1.31 \\
\hline \multirow[t]{2}{*}{ Frontal cortex (BA8) } & 76 & 24 & 27 & 39 & 4.35 & 1.52 \\
\hline & & 29 & 20 & 42 & 4.27 & 1.49 \\
\hline Occipital lobe (BA19) & 89 & 45 & -81 & 6 & 4.30 & 1.50 \\
\hline Angular gyrus (BA39) & 83 & 32 & -54 & 42 & 4.21 & 1.47 \\
\hline Fusiform gyrus (BA37) & 116 & -36 & -59 & -14 & 4.11 & 1.43 \\
\hline Inferior temporal lobe (BA20) & 64 & 36 & -5 & -39 & 4.07 & 1.42 \\
\hline Prefrontal cortex (BA10) & 110 & 30 & 45 & 20 & 3.80 & 1.32 \\
\hline
\end{tabular}

BA, Broadman areas; clusters were considered significant using voxel-wise statistical threshold of $p<0.03$ (FDR corrected for multiple comparisons) with an extent threshold of 60 voxels.

in the posterior cingulate, extending into the precuneus, inferior parietal lobule, superior parietal, lateral temporal, and lateral prefrontal, whereas no significant associations were detected in medial temporal cortical regions [60]. In turn, another study by [61] found only a significant correlation between both neuropathological mechanisms in the inferior temporal region and hippocampal volume in a PiB-positive $\mathrm{HC}$ group. This relationship was not detected either in aMCI (amnestic mild cognitive impairment) or AD groups. The authors explained their results in light of the typical late-onset $\mathrm{AD}$ model which suggests a divergence between both mechanisms, so that $A \beta$ deposition follows at a sustained slow rate towards a plateau $[55,80]$, while atrophy rate hastens as the disease evolves [81]. A recent study by [51] has explored $A \beta$ and neurodegeneration in three different groups: subjects with subjective memory complaints (SCI), aMCI patients, and a group of AD. In this study associations were found between $A \beta$ and atrophy when considering all the groups together, but individually only the SCI group preserved a strong relationship between both events in the regions of highest $A \beta$ load (medial orbitofrontal as well as anterior and posterior cingulate areas). The authors argued that there is a marked interplay between both pathological events very early in prodromal $\mathrm{AD}$, but as the disease progresses other downstream pathological events might be responsible for the ongoing neuronal deterioration. Furthermore, by pooling $\mathrm{HC}$ and $\mathrm{AD}$ patients it was found by [52] associations between increased $\mathrm{A} \beta$ uptake and GM density loss in the hippocampal and amygdala regions, suggesting that toxic effects of $A \beta$ deposition may depend on the region. Nevertheless, the obtained correlations might had resulted from intergroup differences since both groups were merged, as the authors concluded.

It is noteworthy that several studies have found associations when combining different groups. For instance, a study by [60] reported associations in a mixed group composed by $68 \mathrm{PiB}$ negative and $18 \mathrm{PiB}$ positive normal controls, reporting a pattern of association similar to AD. Also, the study by [52] reported associations when joining both groups $\mathrm{HC}$ and $\mathrm{AD}$ patients. In turn, the study by [61] found an interplay between neocortical $\mathrm{PiB}$ and hippocampal volume when pooling 93 normal controls (32 $\mathrm{PiB}$ positive) 33 aMCI (20 PiB positive) and 35 mild AD patients $\mathrm{PiB}$ positive. Finally, the study by [51] reported associations between global measures of $\mathrm{PiB}$ and grey matter atrophy when the SCI, HC, aMCI, and AD groups were assembled, whereas the voxel-to-voxel analysis revealed only significant associations in SCI (with only $39 \%$ of the subjects positive for ${ }^{11} \mathrm{C}-\mathrm{PiB}$ 
PET). In line with these previous reports, we have also searched for associations between $A \beta$ and neurodegeneration by merging $20 \mathrm{PiB}$ positive early $\mathrm{AD}$ and $17 \mathrm{PiB}$ negative $\mathrm{HC}$. The results still show the same lateral temporal areas that we found modestly in $\mathrm{AD}$ group alone extending notably to medial prefrontal, occipital, and lateral parietal. Since our groups were age, sex, and education matched, and that all controls were $\mathrm{PiB}$ negative in contrast to all $\mathrm{PiB}$ positive AD patients, it is likely that the obtained correlations had resulted from AD related mechanisms rather than from other sources of intergroup differences, contrasting to previous studies where heterogenous groups were evaluated. It should also be stressed as a cautionary note that merging both groups might lead to inferences that are not necessarily related to $\mathrm{AD}$ pathological mechanism. Further studies with higher AD sample sizes will be needed to corroborate these disease related outcomes.

Thus, it is notorious the difficulty of neuroimaging studies to uphold a direct link between $A \beta$ and neurodegeneration, with several studies pointing towards a dissociation between $A \beta$ and atrophy as the disease progress $[55,80,82]$. Accordingly, a study by [83] proposed a reformulation of $A \beta$ hypothesis by suggesting a second stage process increasingly independent of the initial $A \beta$ deposition. Hence, it is likely that after $A \beta$ reaches a certain level of accumulation other neuropathological mechanisms are triggered that instead promote atrophy. Thus, as time goes by, and the levels of $A \beta$ deposition increase, achieving eventually a plateau by the time that symptoms manifest [80], the direct mechanisms that account for atrophy became increasingly distant of $A \beta$ burden, being less probable to find associations between the two biomarkers [83]. All this evidence led us to the rationale that areas that undergo neurodegeneration later in the course of the disease have a distinct probability to show associations between $A \beta$ and atrophy. Regarding our results, since the frontal lobe shows some resilience to $A \beta$ deposition, perhaps amyloid deposition is not so distant from atrophy mechanisms so that it is still evidencing in some restricted regions a correlation with GM loss. Regarding the lateral temporal lobe, mainly its posterior regions, there is evidence of a higher rate of atrophy when the disease is detected $[68,84,85]$, indicating that neurodegeneration mechanisms are still very salient and possibly not so distant from abnormal $A \beta$ accumulation. In fact, this is one the areas that best splits MCI groups from $\mathrm{AD}$ groups as reported by some studies [86-88]. In turn, the occipital lobe is also one of the areas that later experiences neurodegeneration [67] and one of the last to undergo fibrillar amyloid aggregation [55], so $A \beta$ might still influencing atrophy in these regions. Interestingly, our pattern of association is quite similar to that one comparing atrophy between $\mathrm{AD}$ and $\mathrm{MCI}$, and the ones that show the rate of change in early $\mathrm{AD}$ (please see $[68,84,85]$ ). As these aforementioned morphometric studies, we found a higher involvement of left hemisphere in the disease, particularly in the associations between $A \beta$ and neurodegeneration.

Moreover, it is likely that amyloid plaques yield uneven effects through different brain areas or even sub-regions, probably reflecting distinct region specific pathological or protective mechanisms, as for example the presence of neurofibrillary tangles [89, 90], disconnection [91, 92], as well as compensation processes $[75,76]$. Thus, while on one hand there is regional susceptibility to $A \beta$ deposition [93], on the other one there is also regional susceptibility to the involvement of $A \beta$ in the neurodegeneration processes [23, 74]. Thus, this might explain why the pattern of amyloid and atrophy is not coherent with the pattern of association between the two biomarkers. Atrophy may not be a mandatory subsequent process of $A \beta$ deposition. In turn, other neuropathological mechanisms might prevail over $\mathrm{A} \beta$ deposition and rather promote atrophy of some regions.

Regarding the neuroinflammation data, different extents and levels of microglial activation have been reported using PET imaging in both $\mathrm{AD}$ and $\mathrm{aMCI}$ patients $[24,25]$. Some have indeed found regions with substantial microglial activation in AD [22, 27, 28, 94-96], whereas others have not [63, 97, 98]. While some have highlighted a pivotal role of neuroinflammation in prodromal AD (MCI) [7, 99-102], others have suggested that microglial activation increased with the progression of the disease $[26,27]$. All this conflicting evidence might point to a fluctuation of reactive microglia cells along the disease [26] reflecting two peaks: an initial antiinflammatory response at the very early stages of the disease (prodromal AD) and a second peak during the conversion from $\mathrm{MCI}$ to $\mathrm{AD}$, possibly representing a pro-inflammatory change [103-106].

In the present study and opposite to the marked $A \beta$ widespread deposition across the brain, an increased ${ }^{11} \mathrm{C}-\mathrm{PK} 11195$ BP was confined to more small brain regions such as: parahippocampal, cingulate, middle temporal, superior parietal, and superior frontal. Our findings were consistent with previous studies 
$[7,27,28,94]$ reporting larger differences in temporoparietal cortex.

Although neuroinflammation is an accepted hallmark of $\mathrm{AD}$, the precise mechanisms by which it might promote cortical atrophy and how it interacts with amyloid plaques have not been firmly established. A few neuroimaging studies have searched for associations between $\mathrm{A} \beta$ and neuroinflammation, whereas studies searching for the associations with GM density are scarce. Even though we were not able to demonstrate at voxel-level a significant interplay between neuroinflammation and the other two neuropathological biomarkers, this could be demonstrated using a more sensitive ROI-based analysis. Regionally we found the most notorious association between GM volume and neuroinflammation in hippocampus and parahippocampal area. In fact, the apparently counterintuitive positive correlations found in these medial temporal areas might suggest a protective role of reactive microglial cells in response to pathological events either it be tau tangles, $A \beta$, or other downstream pathological mechanism. In contrast, the tendency to a negative association between GM volume and neuroinflammation in frontal middle and temporal inferior areas might point to a detrimental role of microglia activation on the structural integrity of these regions.

Thus, it is possible that at the same time point neuroinflammation is associated with cell loss in some regions while older regions from the phylogenetic point of view, such as the hippocampus, may show different effects due an hypercellularity shift. Although this dichotomy is reasonable, given the temporal disparity with which the same neuropathological mechanisms affect different areas of the brain, further studies with higher sample sizes are needed to confirm this theory.

The work by [94] examined the structural changes between the first and second MRI scan (after 24 months) of $\mathrm{AD}$ patients, and they found that areas with high ${ }^{11} \mathrm{C}-(\mathrm{R})-\mathrm{PK} 11195 \mathrm{BP}$ showed the highest rate of atrophy, suggesting that the presence of a local immune response was related with subsequent tissue loss (inferior and middle temporal area/fusiform gyrus/parahippocampal gyrus/posterior cingulate). Also, other two studies have found a linkage between reactive microglia and grey matter atrophy, approximately in the same areas [7, 27]. With regard to the interplay between $A \beta$ and neuroinflammation, in spite of the fact that postmortem literature has shown a spatial relationship between $A \beta$ accumulation and microglial activation [107], our ROI-based results only suggest associations between both in left hippocampus and right superior frontal gyrus. Concerning the neuroimaging literature, a previous study by [28] reported only a negative correlation between ${ }^{11}$ C-PK11195 BP and ${ }^{11} \mathrm{C}-\mathrm{PiB}$ SUVR in the posterior cingulate cortex, denoting that $A \beta$ might not be always the leading cause of microglial activation. Also, a study by [26] argued that some reactive microglia cells might be triggered by other events, since some areas lacked to evidence coupling with amyloid plaques. In the study by [27], it was found that AD patients had significant correlations between both in inferior parietal lobule, superior temporal cortex, precuneus, hippocampus, and parahippocampal gyrus. Moreover, a study by [108] reported positive correlations throughout the cortex in both MCI and AD groups. However, MCI subjects revealed a wider cortical distribution and strong correlations compared to $\mathrm{AD}$. They suggested an early peak of microglial activation in response to the beginning of $A \beta$ deposition in MCI, and a second peak in response to neurofibrillary tangles formation and spread when the disease is diagnosed.

As such, it is likely that our data represent the second peak of microglial activation in the course of the disease. Since associations between $A \beta$ and activated microglia were confined to left hippocampus and right superior frontal lobe, one could speculate that in general neuroinflammation might not be a consequence of fibrillar $A \beta$ deposition at this stage of the disease in which $A \beta$ deposition already reached a plateau. In fact, evidence across studies have demonstrated strong associations of microglial activation with $A \beta$ in early $\mathrm{MCI}[7,26,101,109]$, while in established $\mathrm{AD}$ the associations were stronger with tau tangle burden $[108,110]$. Thus, microglial activation we found might have been triggered by neurofibrillary tangles rather than amyloid, since tau tangles continue increasing in this phase [62]. This potential lack of coupling is biologically plausible since in the aging brain both neuroinflammation and neurodegeneration were found in the absence of $A \beta$ [111]. Moreover, this pathologic event is also present in other neurodegenerative diseases [112, 113], which are not characterized by brain amyloidosis. Several studies failed to show evidence of an association between $A \beta$ load and neuroinflammation $[22,100$, 114]. Our study provides a somewhat reconciling view on this debate.

As such, the complexity and uncertainty about the neuropathological mechanisms underlying $\mathrm{AD}$ and their constant change throughout the disease's 
progression makes of utmost importance to study clearly defined groups as we have done here. Our AD group was clinically well characterized and in the same stage of the disease $(\mathrm{CDR}=1$, with less than 1 year of diagnosis) and all of them were positive for PiB retention. In addition, our controls were matched for age (preventing effects of aging), education (preventing effects of cognitive reserve), and sex (preventing brain and sex differences) and were PiB negative. Thus, it is highly probable that differences arise due to AD-related differences and not due to other group differences.

Nevertheless, our study presents some limitations that should be considered, as the small size of the groups, the lack of follow-up clinically or with imaging data as well as the fact of our AD sample have a probable diagnostic since no postmortem confirmation of AD pathology was possible.

Thus, our results suggest an important, although uneven, role of $A \beta$ in cortical atrophy related to $\mathrm{AD}$, which might depend on regional susceptibility. However, regions that later experience atrophy are more prone to show associations with $A \beta$ since the neurodegenerative mechanisms still noticeable, providing an excellent opportunity to gain insight into the mechanisms underlying the effects of $A \beta$ on atrophy. Thus, despite the fact that $\mathrm{A} \beta$ has a prominent role in the neurogenerative processes involved in $\mathrm{AD}$, our findings provide a reconciling view on the still controversial role of neuroinflammation which might be stage dependent.

\section{ACKNOWLEDGMENTS}

This work was supported by Neuroscience Mantero Belard Prize 2015 (Santa Casa da Misericórdia): Ref: MB-1049-2015. Foundation for Science and Technology, Portugal (UID/NEU/04950/2020, CEE CINST/00041/2018, COMPETE-FEDER (POCI01-0145-FEDER-007440), MEDPERSYST, POCI01-0145-FEDER-016428, DSAIPA/DS/0041/2020 Centro 2020 (CENTRO-01-0145-FEDER-000008: BrainHealth 2020), BIGDATIMAGE, CENTRO01-0145-FEDER-000016, Centro 2020 FEDER, COMPETE.

Authors' disclosures available online (https:// www.j-alz.com/manuscript-disclosures/20-0840r2).

\section{REFERENCES}

[1] Avila J, Pallas N, Bolós M, Sayas CL, Hernandez F (2016) Intracellular and extracellular microtubule associated protein tau as a therapeutic target in Alzheimer disease and other tauopathies. Expert Opin Ther Targets 20, 653-661.

[2] Hardy J, Selkoe DJ (2002) The amyloid hypothesis of Alzheimer's disease: Progress and problems on the road to therapeutics. Science 297, 353-356.

[3] Amor S, Puentes F, Baker D, Van Der Valk P (2010) Inflammation in neurodegenerative diseases. Immunology 129, 154-169.

[4] Heneka MT, Carson MJ, Khoury J El, Landreth GE, Brosseron F, Feinstein DL, Jacobs AH, Wyss-Coray T, Vitorica J, Ransohoff RM, Herrup K, Frautschy SA, Finsen B, Brown GC, Verkhratsky A, Yamanaka K, Koistinaho J, Latz E, Halle A, Petzold GC, Town T, Morgan D, Shinohara ML, Perry VH, Holmes C, Bazan NG, Brooks DJ, Hunot S, Joseph B, Deigendesch N, Garaschuk O, Boddeke E, Dinarello CA, Breitner JC, Cole GM, Golenbock DT, Kummer MP (2015) Neuroinflammation in Alzheimer's disease. Lancet Neurol 14, 388-405.

[5] Pasqualetti G, Brooks DJ, Edison P (2015) The role of neuroinflammation in dementias. Curr Neurol Neurosci $\operatorname{Rep} \mathbf{1 5}, 17$.

[6] Ard M, Cole G, Wei J, Mehrle A, Fratkin J (1996) Scavenging of Alzheimer's amyloid $\beta$-protein by microglia in culture. J Neurosci Res 43, 190-202.

[7] Hamelin L, Lagarde J, Dorothée G, Leroy C, Labit M, Comley RA, de Souza LC, Corne H, Dauphinot L, Bertoux M, Dubois B, Gervais P, Colliot O, Potier MC, Bottlaender M, Sarazin M (2016) Early and protective microglial activation in Alzheimer's disease: A prospective study using 18F-DPA-714 PET imaging. Brain 139, 12521264.

[8] Paresce DM, Chung H, Maxfield FR (1997) Slow degradation of aggregates of the Alzheimer's disease amyloid-protein by microglial cells. J Biol Chem 272, 29390-29397.

[9] Wisniewski HM, Wegiel J, Wang KC, Lach B (1992) Ultrastructural studies of the cells forming amyloid in the cortical vessel wall in Alzheimer's disease. Acta Neuropathol 84, 117-127.

[10] Akiyama H, Barger S, Barnum S, Bradt B, Bauer J, Cole GM, Cooper NR, Eikelenboom P, Emmerling M, Fiebich BL, Finch CE, Frautschy S, Griffin WS., Hampel H, Hull M, Landreth G, Lue L, Mrak R, Mackenzie IR, McGeer PL, O’Banion MK, Pachter J, Pasinetti G, Plata-Salaman C, Rogers J, Rydel R, Shen Y, Streit W, Strohmeyer R, Tooyoma I, Van Muiswinkel FL, Veerhuis R, Walker D, Webster S, Wegrzyniak B, Wenk G, Wyss-Coray T (2000) Inflammation and Alzheimer's disease. Neurobiol Aging 21, 383-421.

[11] Maphis N, Xu G, Kokiko-Cochran ON, Jiang S, Cardona A, Ransohoff RM, Lamb BT, Bhaskar K (2015) Reactive microglia drive tau pathology and contribute to the spreading of pathological tau in the brain. Brain 138, 1738-1755.

[12] McGeer PL, McGeer EG (2001) Inflammation, autotoxicity and Alzheimer disease. Neurobiol Aging 22, 799-809.

[13] Masters CL, Cappai R, Barnham KJ, Villemagne VL (2006) Molecular mechanisms for Alzheimer's disease: Implications for neuroimaging and therapeutics. $\mathrm{J} \mathrm{Neu}$ rochem $\mathbf{9 7}, 1700-1725$.

[14] Haga S, Akai K, Ishii T (1989) Demonstration of microglial cells in and around senile (neuritic) plaques in the Alzheimer brain. An immunohistochemical study using a novel monoclonal antibody. Acta Neuropathol 77, 569-75. 
[15] Jones SE, Buchbinder BR, Aharon I (2000) Threedimensional mapping of cortical thickness using Laplace's equation. Hum Brain Mapp 11, 12-32.

[16] Mcgeer PL, Mcgeer EG (2002) Local neuroinflammation and the progression of Alzheimer's disease. J Neurovirol 8, 529-538.

[17] Perlmutter LS, Barron E, Chui HC (1990) Morphologic association between microglia and senile plaque amyloid in Alzheimer's disease. Neurosci Lett 119, 32-36.

[18] Stalder M, Phinney A, Probst A, Sommer B, Staufenbiel M, Jucker M (1999) Association of microglia with amyloid plaques in brains of APP23 transgenic mice. Am J Pathol 154, 1673-1684.

[19] Shah F, Hume SP, Pike VW, Ashworth S, McDermott J (1994) Synthesis of the enantiomers of [N-methyl11C]PK 11195 and comparison of their behaviours as radioligands for PK binding sites in rats. Nucl Med Biol 21, 573-581.

[20] Klunk WE, Engler H, Nordberg A, Wang Y, Blomqvist G, Holt DP, Bergström M, Savitcheva I, Huang G-F, Estrada S, Ausén B, Debnath ML, Barletta J, Price JC, Sandell J, Lopresti BJ, Wall A, Koivisto P, Antoni G, Mathis CA, Långström B (2004) Imaging brain amyloid in Alzheimer's disease with Pittsburgh Compound-B. Ann Neurol 55, 306-319.

[21] Archer HA, Edison P, Brooks DJ, Barnes J, Frost C, Yeatman T, Fox NC, Rossor MN (2006) Amyloid load and cerebral atrophy in Alzheimer's disease: An 11CPIB positron emission tomography study. Ann Neurol 60, 145-147.

[22] Edison P, Archer HA, Gerhard A, Hinz R, Pavese N, Turkheimer FE, Hammers A, Tai YF, Fox N, Kennedy A, Rossor M, Brooks DJ (2008) Microglia, amyloid, and cognition in Alzheimer's disease: An [11C](R)PK11195-PET and [11C]PIB-PET study. Neurobiol Dis 32, 412-419.

[23] Jack CR, Lowe VJ, Senjem ML, Weigand SD, Kemp BJ, Shiung MM, Knopman DS, Boeve BF, Klunk WE, Mathis CA, Petersen RC (2008) 11C PiB and structural MRI provide complementary information in imaging of Alzheimer's disease and amnestic mild cognitive impairment. Brain 131, 665-680.

[24] Stefaniak J, O'Brien J (2016) Imaging of neuroinflammation in dementia: A review. J Neurol Neurosurg Psychiatry 87, 21-8.

[25] Bradburn S, Murgatroyd C, Ray N (2019) Neuroinflammation in mild cognitive impairment and Alzheimer's disease: A meta-analysis. Ageing Res Rev 50, 1-8.

[26] Fan Z, Brooks DJ, Okello A, Edison P (2017) An early and late peak in microglial activation in Alzheimer's disease trajectory. Brain 140, 792-803.

[27] Kreisl WC, Lyoo CH, McGwier M, Snow J, Jenko KJ, Kimura N, Corona W, Morse CL, Zoghbi SS, Pike VW, McMahon FJ, Turner RS, Innis RB (2013) In vivo radioligand binding to translocator protein correlates with severity of Alzheimer's disease. Brain 136, 2228-2238.

[28] Yokokura M, Mori N, Yagi S, Yoshikawa E, Kikuchi M, Yoshihara Y, Wakuda T, Sugihara G, Takebayashi K, Suda S, Iwata Y, Ueki T, Tsuchiya KJ, Suzuki K, Nakamura K, Ouchi Y (2011) In vivo changes in microglial activation and amyloid deposits in brain regions with hypometabolism in Alzheimer's disease. Eur J Nucl Med Mol Imaging 38, 343-351.

[29] American Psychiatric Association (2000) Diagnostic and Statistical Manual of Mental Disorders (DSM-IV-TR), Washington, DC.
[30] McKhann GM, Knopman DS, Chertkow H, Hyman BT, Jack CR, Kawas CH, Klunk WE, Koroshetz WJ, Manly JJ, Mayeux R, Mohs RC, Morris JC, Rossor MN, Scheltens P, Carrillo MC, Thies B, Weintraub S, Phelps CH (2011) The diagnosis of dementia due to Alzheimer's disease: Recommendations from the National Institute on Aging-Alzheimer's Association workgroups on diagnostic guidelines for Alzheimer's disease. Alzheimers Dement 7, 263-269.

[31] Alves C, Jorge L, Canário N, Santiago B, Santana I, Castelhano J, Ambrósio AF, Bernardes R, Castelo-Branco M (2019) Interplay between macular retinal changes and white matter integrity in early Alzheimer's disease. $J$ Alzheimers Dis 70, 723-732.

[32] Ginó S, Mendes T, Ribeiro F, Mendonça A, Guerreiro M, Garcia C (2008) Escala de Queixas de Memória [Subjective Memory Complaints]. In Grupo de Estudos de Envelhecimento Cerebral e Demências [Study Group on Brain Aging and Dementia]. Escalas e testes na demência [Scales and tests in dementia], Mendonça C, Garcia C, Guerreiro M, eds. Lisbon: GEECD, pp. 116-120.

[33] Schmand B, Jonker C, Hooijer C, Lindeboom J (1996) Subjective memory complaints may announce dementia. Neurology 46, 121-125.

[34] Freitas S, Simões MR, Alves L, Santana I (2011) Montreal Cognitive Assessment (MoCA): Normative study for the Portuguese population. J Clin Exp Neuropsychol 33, 989-996.

[35] Lawton MP, Brody EM (1969) Assessment of older people: Self-maintaining and instrumental activities of daily living. Gerontologist 9, 179-186.

[36] Madureira S, Verdelho A (2008) Escala de Actividades Instrumentais de Vida Diária [Instrumental Activities of Daily Living]. In Grupo de Estudos de Envelhecimento Cerebral e Demências [Study Group on Brain Aging and Dementia]. Escalas e testes na demência [Scales and tests in dementia], Mendonça C, Garcia C, Guerreiro M, eds. Lisbon: GEECD, pp. 121-124.

[37] Barreto J, Leuschner A, Santos F, Sobral M (2008) Escala de Depressão Geriátrica [Geriatric Depressive Scale]. In Grupo de Estudos de Envelhecimento Cerebral $e$ Demências [Study Group on Brain Aging and Dementia]. Escalas e testes na demência [Scales and tests in dementia], Mendonça C, Garcia C, Guerreiro M, eds. Lisbon: GEECD, pp. 69-72.

[38] Yesavage JA, Brink TL, Rose TL, Lum O, Huang V, Adey M, Leirer VO (1983) Development and validation of a geriatric depression screening scale: A preliminary report. J Psychiatr Res 17, 37-49.

[39] Jansen WJ, Ossenkoppele R, Knol DL, Tijms BM, Scheltens P, Verhey FRJ, Visser PJ, Aalten P, Aarsland $\mathrm{D}$, Alcolea D, Alexander M, Almdahl IS, Arnold SE, Baldeiras I, Barthel H, Van Berckel BNM, Bibeau K, Blennow K, Brooks DJ, Van Buchem MA, Camus V, Cavedo E, Chen K, Chetelat G, Cohen AD, Drzezga A, Engelborghs S, Fagan AM, Fladby T, Fleisher AS, Van Der Flier WM, Ford L, Forster S, Fortea J, Foskett N, Frederiksen KS, Freund-Levi Y, Frisoni GB, Froelich L, Gabryelewicz T, Gill KD, Gkatzima O, Gomez-Tortosa E, Gordon MF, Grimmer T, Hampel H, Hausner L, Hellwig S, Herukka SK, Hildebrandt H, Ishihara L, Ivanoiu A, Jagust WJ, Johannsen P, Kandimalla R, Kapaki E, KlimkowiczMrowiec A, Klunk WE, Kohler S, Koglin N, Kornhuber J, Kramberger MG, Van Laere K, Landau SM, Lee DY, De Leon M, Lisetti V, Lleo A, Madsen K, Maier W, Marcusson 
J, Mattsson N, De Mendonca A, Meulenbroek O, Meyer PT, Mintun MA, Mok V, Molinuevo JL, Mollergard HM, Morris JC, Mroczko B, Van Der Mussele S, Na DL, Newberg A, Nordberg A, Nordlund A, Novak GP, Paraskevas GP, Parnetti L, Perera G, Peters O, Popp J, Prabhakar S, Rabinovici GD, Ramakers IHGB, Rami L, De Oliveira CR, Rinne JO, Rodrigue KM, Rodriguez-Rodriguez E, Roe CM, Rot U, Rowe CC, Ruther E, Sabri O, SanchezJuan P, Santana I, Sarazin M, Schroder J, Schutte C, Seo SW, Soetewey F, Soininen H, Spiru L, Struyfs H, Teunissen CE, Tsolaki M, Vandenberghe R, Verbeek MM, Villemagne VL, Vos SJB, Van Waalwijk Van Doorn LJC, Waldemar G, Wallin A, Wallin AK, Wiltfang J, Wolk DA, Zboch M, Zetterberg H (2015) Prevalence of cerebral amyloid pathology in persons without dementia: A meta-analysis. JAMA 313, 1924-1938.

[40] Ashburner J, Friston KJ (2005) Unified segmentation. Neuroimage 26, 839-851.

[41] Ashburner J (2007) A fast diffeomorphic image registration algorithm. Neuroimage 38, 95-113.

[42] Ashburner J, Friston KJ (2000) Voxel-based morphometry-the methods. Neuroimage 11, 805-821.

[43] Kikinis R, Pieper SD, Vosburgh KG (2014) 3D slicer: A platform for subject-specific image analysis, visualization, and clinical support. In Intraoperative Imaging and ImageGuided Therapy, Jolesz FA, ed. Springer New York, NY, pp. 277-289.

[44] Oliveira F, Leuzy A, Castelhano J, Chiotis K, Hasselbalch SG, Rinne J, Mendonça A, Otto M, Lleó A, Santana I, Johansson J, Anderl-Straub S, Arnim C, Beer A, Blesa R, Fortea J, Sanna-Kaisa H, Portelius E, Pannee J, Zetterberg H, Blennow K, Moreira AP, Abrunhosa A, Nordberg A, Castelo-Branco M (2018) Data driven diagnostic classification in Alzheimer's disease based on different reference regions for normalization of PiB-PET images and correlation with CSF concentrations of $\mathrm{A} \beta$ species. NeuroImage Clin 20, 603-610.

[45] Bonilla JF, Carril JM (2013) Molecular neuroimaging in degenerative dementias. Rev Española Med Nucl Imagen Mol (English Ed) 32, 301-309.

[46] McNamee RL, Yee S-H, Price JC, Klunk WE, Rosario B, Weissfeld L, Ziolko S, Berginc M, Lopresti B, Dekosky S, Mathis CA (2009) Consideration of optimal time window for Pittsburgh compound B PET summed uptake measurements. J Nucl Med 50, 348-55.

[47] Ichise M, Liow J-S, Lu J-Q, Takano A, Model K, Toyama H, Suhara T, Suzuki K, Innis RB, Carson RE (2003) Linearized reference tissue parametric imaging methods: Application to [11C]DASB positron emission tomography studies of the serotonin transporter in human brain. $J$ Cereb Blood Flow Metab 23, 1096-1112.

[48] Yaqub M, van Berckel BN, Schuitemaker A, Hinz R, Turkheimer FE, Tomasi G, Lammertsma AA, Boellaard $\mathrm{R}$ (2012) Optimization of supervised cluster analysis for extracting reference tissue input curves in (R)[11C]PK11195 brain PET studies. J Cereb Blood Flow Metab 32, 1600-1608.

[49] Casanova R, Srikanth R, Baer A, Laurienti PJ, Burdette JH, Hayasaka S, Flowers L, Wood F, Maldjian JA (2007) Biological parametric mapping: A statistical toolbox for multimodality brain image analysis. Neuroimage 34, 137-143.

[50] Tzourio-Mazoyer N, Landeau B, Papathanassiou D, Crivello F, Etard O, Delcroix N, Mazoyer B, Joliot M (2002) Automated anatomical labeling of activations in SPM using a macroscopic anatomical parcellation of the MNI MRI single-subject brain. Neuroimage 15, 273-289.

[51] Chételat G, Villemagne VL, Bourgeat P, Pike KE, Jones G, Ames D, Ellis KA, Szoeke C, Martins RN, O'Keefe GJ, Salvado O, Masters CL, Rowe CC (2010) Relationship between atrophy and $\beta$-amyloid deposition in Alzheimer's disease. Ann Neurol 67, 317-324.

[52] Frisoni GB, Lorenzi M, Caroli A, Kemppainen N, Någren K, Rinne JO (2009) In vivo mapping of amyloid toxicity in Alzheimer disease. Neurology 72, 1504-1511.

[53] Hardy J, Higgins G (1992) Alzheimer's disease: The amyloid cascade hypothesis. Science 256, 184-185.

[54] Risacher SL, Wudunn D, Pepin SM, MaGee TR, McDonald BC, Flashman LA, Wishart HA, Pixley HS, Rabin LA, Paré N, Englert JJ, Schwartz E, Curtain JR, West JD, O'Neill DP, Santulli RB, Newman RW, Saykin AJ (2013) Visual contrast sensitivity in Alzheimer's disease, mild cognitive impairment, and older adults with cognitive complaints. Neurobiol Aging 34, 1133-1144.

[55] Engler H, Forsberg A, Almkvist O, Blomquist G, Larsson E, Savitcheva I, Wall A, Ringheim A, Langstrom B, Nordberg A (2006) Two-year follow-up of amyloid deposition in patients with Alzheimer's disease. Brain 129, 2856-2866.

[56] Busatto GF, Diniz BS, Zanetti MV (2008) Voxel-based morphometry in Alzheimer's disease. Expert Rev Neurother 8, 1691-1702.

[57] Whitwell JL, Josephs KA, Murray ME, Kantarci K, Przybelski SA, Weigand SD, Vemuri P, Senjem ML, Parisi JE, Knopman DS, Boeve BF, Petersen RC, Dickson DW, Jack CR (2008) MRI correlates of neurofibrillary tangle pathology at autopsy: A voxel-based morphometry study. Neurology 71, 743-749.

[58] Matsuda H (2013) Voxel-based morphometry of brain MRI in normal aging and Alzheimer's disease. Aging Dis 4, 29-37.

[59] Wang W-Y, Yu J-T, Liu Y, Yin R-H, Wang H-F, Wang J, Tan L, Radua J, Tan L (2015) Voxel-based meta-analysis of grey matter changes in Alzheimer's disease. Transl Neurodegener 4, 6 .

[60] Becker JA, Hedden T, Carmasin J, Maye J, Rentz DM, Putcha D, Fischl B, Greve DN, Marshall GA, Salloway S, Marks D, Buckner RL, Sperling RA, Johnson KA (2011) Amyloid- $\beta$ associated cortical thinning in clinically normal elderly. Ann Neurol 69, 1032-1042.

[61] Bourgeat P, Chetelat G, Villemagne VL, Fripp J, Raniga P, Pike K, Acosta O, Szoeke C, Ourselin S, Ames D, Ellis KA, Martins RN, Masters CL, Rowe CC, Salvado O, AIBL Research Group (2010) Beta-amyloid burden in the temporal neocortex is related to hippocampal atrophy in elderly subjects without dementia. Neurology $\mathbf{7 4}$, 121-127.

[62] Braak H, Braak E (1991) Neuropathological stageing of Alzheimer-related changes. Acta Neuropathol 82, 239-259.

[63] Wiley CA, Lopresti BJ, Venneti S, Price J, Klunk WE, DeKosky ST, Mathis CA (2009) Carbon 11-labeled Pittsburgh compound B and carbon 11-labeled (R)-PK11195 positron emission tomographic imaging in Alzheimer disease. Arch Neurol 66, 60-67.

[64] Baron JC, Chételat G, Desgranges B, Perchey G, Landeau B, de la Sayette V, Eustache F (2001) In vivo mapping of gray matter loss with voxel-based morphometry in mild Alzheimer's disease. Neuroimage 14, 298-309. 
[65] Fox NC, Freeborough PA, Rossor MN (1996) Visualisation and quantification of rates of atrophy in Alzheimer's disease. Lancet 348, 94-97.

[66] Jack CR, Petersen RC, O’Brien PC, Tangalos EG (1992) MR-based hippocampal volumetry in the diagnosis of Alzheimer's disease. Neurology 42, 183-188.

[67] McDonald CR, McEvoy LK, Gharapetian L, FennemaNotestine C, Hagler DJ, Holland D, Koyama A, Brewer JB, Dale AM, Alzheimer's Disease Neuroimaging Initiative (2009) Regional rates of neocortical atrophy from normal aging to early Alzheimer disease. Neurology 73, 457-465.

[68] Whitwell JL, Przybelski SA, Weigand SD, Knopman DS, Boeve BF, Petersen RC, Jack CR (2007) 3D maps from multiple MRI illustrate changing atrophy patterns as subjects progress from mild cognitive impairment to Alzheimer's disease. Brain 130, 1777-1786.

[69] Walsh DM, Selkoe DJ (2007) A beta oligomers - a decade of discovery. J Neurochem 101, 1172-1184.

[70] Furst AJ, Rabinovici GD, Rostomian AH, Steed T, Alkalay A, Racine C, Miller BL, Jagust WJ (2012) Cognition, glucose metabolism and amyloid burden in Alzheimer's disease. Neurobiol Aging 33, 215-225.

[71] Lockhart A, Lamb JR, Osredkar T, Sue LI, Joyce JN, Ye L, Libri V, Leppert D, Beach TG (2007) PIB is a nonspecific imaging marker of amyloid-beta $(A \beta)$ peptiderelated cerebral amyloidosis. Brain 130, 2607-2615.

[72] Mormino EC, Kluth JT, Madison CM, Rabinovici GD, Baker SL, Miller BL, Koeppe RA, Mathis CA, Weiner MW, Jagust WJ (2009) Episodic memory loss is related to hippocampal-mediated B-amyloid deposition in elderly subjects. Brain 132, 1310-1323.

[73] Thal DR, Rüb U, Schultz C, Sassin I, Ghebremedhin E, Del Tredici K, Braak E, Braak H (2000) Sequence of A $\beta$ protein deposition in the human medial temporal lobe. $J$ Neuropathol Exp Neurol 59, 733-748.

[74] La Joie R, Perrotin A, Barre L, Hommet C, Mezenge F, Ibazizene M, Camus V, Abbas A, Landeau B, Guilloteau D, de La Sayette V, Eustache F, Desgranges B, Chetelat G (2012) Region-specific hierarchy between atrophy, hypometabolism, and $\beta$-amyloid (A $\beta$ ) load in Alzheimer's disease dementia. J Neurosci 32, 16265-16273.

[75] Schwindt GC, Black SE (2009) Functional imaging studies of episodic memory in Alzheimer's disease: A quantitative meta-analysis. Neuroimage 45, 181-190.

[76] DeKosky ST, Ikonomovic MD, Styren SD, Beckett L, Wisniewski S, Bennett DA, Cochran EJ, Kordower JH, Mufson EJ (2002) Upregulation of choline acetyltransferase activity in hippocampus and frontal cortex of elderly subjects with mild cognitive impairment. Ann Neurol 51, 145-155.

[77] Ikonomovic MD, Abrahamson EE, Isanski BA, Wuu J, Mufson EJ, DeKosky ST (2007) Superior frontal cortex cholinergic axon density in mild cognitive impairment and early Alzheimer disease. Arch Neurol 64, 1312-1317.

[78] Jacobs B, Driscoll L, Schall M (1997) Life-span dendritic and spine changes in areas 10 and 18 of human cortex: A quantitative Golgi study. J Comp Neurol 386, 661-80.

[79] Kemppainen NM, Aalto S, Wilson IA, Nagren K, Helin S, Bruck A, Oikonen V, Kailajarvi M, Scheinin M, Viitanen M, Parkkola R, Rinne JO (2006) Voxel-based analysis of PET amyloid ligand [11C]PIB uptake in Alzheimer disease. Neurology 67, 1575-1580.

[80] Jack CR, Lowe VJ, Weigand SD, Wiste HJ, Senjem ML, Knopman DS, Shiung MM, Gunter JL, Boeve BF, Kemp
BJ, Weiner M, Petersen RC (2009) Serial PIB and MRI in normal, mild cognitive impairment and Alzheimer's disease: Implications for sequence of pathological events in Alzheimer's disease. Brain 132, 1355-1365.

[81] Chan D, Janssen JC, Whitwell JL, Watt HC, Jenkins R, Frost C, Rossor MN, Fox NC (2003) Change in rates of cerebral atrophy over time in early-onset Alzheimer's disease: Longitudinal MRI study. Lancet 362, 1121-1122.

[82] Scheinin NM, Aalto S, Koikkalainen J, Lotjonen J, Karrasch M, Kemppainen N, Viitanen M, Nagren K, Helin S, Scheinin M, Rinne JO (2009) Follow-up of [11C]PIB uptake and brain volume in patients with Alzheimer disease and controls. Neurology 73, 1186-1192.

[83] Hyman BT (2011) Amyloid-dependent and amyloidindependent stages of Alzheimer disease. Arch Neurol 68, 1062.

[84] Chételat G, Desgranges B, de la Sayette V, Viader F, Eustache F, Baron J-C (2002) Mapping gray matter loss with voxel-based morphometry in mild cognitive impairment. Neuroreport 13, 1939-1943.

[85] Whitwell JL (2010) Progression of atrophy in Alzheimer's disease and related disorders. Neurotox Res 18, 339-346.

[86] Convit A, De Leon MJ, Tarshish C, De Santi S, Tsui W, Rusinek H, George A (1997) Specific hippocampal volume reductions in individuals at risk for Alzheimer's disease. Neurobiol Aging 18, 131-138.

[87] De Santi S, de Leon MJ, Rusinek H, Convit A, Tarshish CY, Roche A, Tsui WH, Kandil E, Boppana M, Daisley K, Wang GJ, Schlyer D, Fowler J (2001) Hippocampal formation glucose metabolism and volume losses in MCI and AD. Neurobiol Aging 22, 529-39.

[88] Ikeda M, Tanabe H, Nakagawa Y, Kazui H, Oi H, Yamazaki H, Harada K, Nishimura T (1994) MRI-based quantitative assessment of the hippocampal region in very mild to moderate Alzheimer's disease. Neuroradiology 36, 7-10.

[89] Ballatore C, Lee VM-Y, Trojanowski JQ (2007) Taumediated neurodegeneration in Alzheimer's disease and related disorders. Nat Rev Neurosci 8, 663-672.

[90] Bennett DA, Schneider JA, Wilson RS, Bienias JL, Arnold SE (2004) Neurofibrillary tangles mediate the association of amyloid load with clinical Alzheimer disease and level of cognitive function. Arch Neurol 61, 378 .

[91] Bozzali M, Parker GJM, Serra L, Embleton K, Gili T, Perri R, Caltagirone C, Cercignani M (2011) Anatomical connectivity mapping: A new tool to assess brain disconnection in Alzheimer's disease. Neuroimage 54, 2045-2051.

[92] Gili T, Cercignani M, Serra L, Perri R, Giove F, Maraviglia B, Caltagirone C, Bozzali M (2011) Regional brain atrophy and functional disconnection across Alzheimer's disease evolution. J Neurol Neurosurg Psychiatry 82, 58-66.

[93] Buckner RL, Sepulcre J, Talukdar T, Krienen FM, Liu H, Hedden T, Andrews-Hanna JR, Sperling RA, Johnson KA (2009) Cortical hubs revealed by intrinsic functional connectivity: Mapping, assessment of stability, and relation to Alzheimer's disease. J Neurosci 29, 1860-1873.

[94] Cagnin A, Brooks DJ, Kennedy AM, Gunn RN, Myers R, Turkheimer FE, Jones T, Banati RB (2001) In-vivo measurement of activated microglia in dementia. Lancet $\mathbf{3 5 8}$, 461-467.

[95] Esposito G, Giovacchini G, Liow J-S, Bhattacharjee AK, Greenstein D, Schapiro M, Hallett M, Herscovitch P, 
Eckelman WC, Carson RE, Rapoport SI (2008) Imaging neuroinflammation in Alzheimer's disease with radiolabeled arachidonic acid and PET. J Nucl Med 49, 1414-21.

[96] Tomasi G, Edison P, Bertoldo A, Roncaroli F, Singh P, Gerhard A, Cobelli C, Brooks DJ, Turkheimer FE (2008) Novel reference region model reveals increased microglial and reduced vascular binding of 11C-(R)-PK11195 in patients with Alzheimer's disease. J Nucl Med 49, 12491256.

[97] Groom G, Junck L, Foster NL, Frey KA, Kuhl DE (1995) PET of peripheral benzodiazepine binding sites in the microgliosis of Alzheimer's disease. J Nucl Med 36, 22072210.

[98] Kropholler MA, Boellaard R, van Berckel BN, Schuitemaker A, Kloet RW, Lubberink MJ, Jonker C, Scheltens P, Lammertsma AA (2007) Evaluation of reference regions for (R) -[11C]PK11195 studies in Alzheimer's disease and mild cognitive impairment. $J$ Cereb Blood Flow Metab 27, 1965-1974.

[99] Calsolaro V, Edison P (2016) Neuroinflammation in Alzheimer's disease: Current evidence and future directions. Alzheimers Dement 12, 719-732.

[100] Okello A, Edison MP, Archer MH, Turkheimer MF, Kennedy J, Bullock MR, Walker MrcpZ, Kennedy A, Fox N, Rossor M, Brooks DsD (2009) Microglial activation and amyloid deposition in mild cognitive impairment $\mathrm{A}$ PET study. Neurology 72, 56-62.

[101] Parbo P, Ismail R, Hansen KV, Amidi A, Mårup FH, Gottrup H, Brændgaard H, Eriksson BO, Eskildsen SF, Lund TE, Tietze A, Edison P, Pavese N, Stokholm MG, Borghammer P, Hinz R, Aanerud J, Brooks DJ (2017) Brain inflammation accompanies amyloid in the majority of mild cognitive impairment cases due to Alzheimer's disease. Brain 140, 2002-2011.

[102] Yasuno F, Kosaka J, Ota M, Higuchi M, Ito H, Fujimura Y, Nozaki S, Takahashi S, Mizukami K, Asada T, Suhara T (2012) Increased binding of peripheral benzodiazepine receptor in mild cognitive impairment-dementia converters measured by positron emission tomography with [11C]DAA1106. Psychiatry Res Neuroimaging 203, 67-74.

[103] Cai Z, Hussain MD, Yan LJ (2014) Microglia, neuroinflammation, and beta-amyloid protein in Alzheimer's disease. Int J Neurosci 124, 307-321.

[104] Prokop S, Miller KR, Heppner FL (2013) Microglia actions in Alzheimer's disease. Acta Neuropathol 126, 461-477.
[105] Varnum MM, Ikezu T (2012) The classification of microglial activation phenotypes on neurodegeneration and regeneration in alzheimer's disease brain. Arch Immunol Ther Exp 60, 251-266.

[106] Zotova E, Bharambe V, Cheaveau M, Morgan W, Holmes C, Harris S, Neal JW, Love S, Nicoll JAR, Boche D (2013) Inflammatory components in human Alzheimer's disease and after active amyloid- $\beta 42$ immunization. Brain 136, 2677-2696.

[107] McGeer PL, Itagaki S, Tago H, McGeer EG (1987) Reactive microglia in patients with senile dementia of the Alzheimer type are positive for the histocompatibility glycoprotein HLA-DR. Neurosci Lett 79, 195-200.

[108] Dani M, Wood M, Mizoguchi R, Fan Z, Walker Z, Morgan R, Hinz R, Biju M, Kuruvilla T, Brooks DJ, Edison P (2018) Microglial activation correlates in vivo with both tau and amyloid in Alzheimer's disease. Brain 141, 27402754.

[109] Villemagne VL, Burnham S, Bourgeat P, Brown B, Ellis KA, Salvado O, Szoeke C, Macaulay SL, Martins R, Maruff P, Ames D, Rowe CC, Masters CL (2013) Amyloid $\beta$ deposition, neurodegeneration, and cognitive decline in sporadic Alzheimer's disease: A prospective cohort study. Lancet Neurol 12, 357-367.

[110] Serrano-Pozo A, Mielke ML, Gómez-Isla T, Betensky RA, Growdon JH, Frosch MP, Hyman BT (2011) Reactive glia not only associates with plaques but also parallels tangles in Alzheimer's disease. Am J Pathol 179, 1373-1384.

[111] von Bernhardi R, Eugenín-von Bernhardi L, Eugenín J (2015) Microglial cell dysregulation in brain aging and neurodegeneration. Front Aging Neurosci 7, 124.

[112] Cagnin A, Rossor M, Sampson EL, MacKinnon T, Banati RB (2004) In vivo detection of microglial activation in frontotemporal dementia. Ann Neurol 56, 894-897.

[113] Surendranathan A, Rowe JB, O’Brien JT (2015) Neuroinflammation in Lewy body dementia. Parkinsonism Relat Disord 21, 1398-1406.

[114] Carter SF, Schöll M, Almkvist O, Wall A, Engler H, Långström B, Nordberg A (2012) Evidence for astrocytosis in prodromal Alzheimer disease provided by 11C-deuterium-L-deprenyl: A multitracer PET paradigm combining 11C-Pittsburgh compound B and 18F-FDG. $J$ Nucl Med 53, 37-46. 